\title{
Transcriptome and proteome profiling reveal complementary scavenger and immune features of rat liver sinusoidal endothelial cells and liver macrophages
}

Sabin Bhandari ${ }^{1}$, Ruomei Li ${ }^{1}$, Jaione Simón-Santamaría ${ }^{1}$, Peter McCourt ${ }^{1}$, Steinar Daae Johansen ${ }^{1,2}$, Bård Smedsrød ${ }^{1 *}$, Inigo Martinez-Zubiaurre ${ }^{3}$ and Karen Kristine Sørensen ${ }^{1}$

\begin{abstract}
Background: Liver sinusoidal endothelial cells (LSECs) and Kupffer cells (KCs; liver resident macrophages) form the body's most effective scavenger cell system for the removal of harmful blood-borne substances, ranging from modified self-proteins to pathogens and xenobiotics. Controversies in the literature regarding the LSEC phenotype pose a challenge when determining distinct functionalities of KCs and LSECs. This may be due to overlapping functions of the two cells, insufficient purification and/or identification of the cells, rapid dedifferentiation of LSECS in vitro, or species differences. We therefore characterized and quantitatively compared expressed gene products of freshly isolated, highly pure LSECS (fenestrated SE-1/FcyRllb2 ${ }^{+}$) and KCS (CD11b/C ${ }^{+}$) from Sprague Dawley, Crl:CD (SD), male rats using high throughput mRNA-sequencing and label-free proteomics.

Results: We observed a robust correlation between the proteomes and transcriptomes of the two cell types. Integrative analysis of the global molecular profile demonstrated the immunological aspects of LSECs. The constitutive expression of several immune genes and corresponding proteins of LSECs bore some resemblance with the expression in macrophages. LSECs and KCs both expressed high levels of scavenger receptors (SR) and Ctype lectins. Equivalent expression of SR-A1 (Msr1), mannose receptor (Mrc1), SR-B1 (Scarb1), and SR-B3 (Scarb2) suggested functional similarity between the two cell types, while functional distinction between the cells was evidenced by LSEC-specific expression of the SRs stabilin-1 (Stab1) and stabilin-2 (Stab2), and the C-type lectins LSECtin (Clec4g) and DC-SIGNR (Clec4m). Many immune regulatory factors were differentially expressed in LSECs and $\mathrm{KCS}$, with one cell predominantly expressing a specific cytokine/chemokine and the other cell the cognate receptor, illustrating the complex cytokine milieu of the sinusoids. Both cells expressed genes and proteins involved in antigen processing and presentation, and lymphocyte co-stimulation.

(Continued on next page)
\end{abstract}

\footnotetext{
* Correspondence: bard.smedsrod@uit.no

'Department of Medical Biology, Vascular Biology Research Group, University

of Tromsø (UiT) -The Arctic University of Norway, Hansine Hansens veg 18,

N-9037 Tromsø, Norway

Full list of author information is available at the end of the article
}

\section{$\triangle B M C$}

(c) The Author(s). 2020 Open Access This article is licensed under a Creative Commons Attribution 4.0 International License, which permits use, sharing, adaptation, distribution and reproduction in any medium or format, as long as you give appropriate credit to the original author(s) and the source, provide a link to the Creative Commons licence, and indicate if changes were made. The images or other third party material in this article are included in the article's Creative Commons licence, unless indicated otherwise in a credit line to the material. If material is not included in the article's Creative Commons licence and your intended use is not permitted by statutory regulation or exceeds the permitted use, you will need to obtain permission directly from the copyright holder. To view a copy of this licence, visit http://creativecommons.org/licenses/by/4.0/ The Creative Commons Public Domain Dedication waiver (http://creativecommons.org/publicdomain/zero/1.0/) applies to the data made available in this article, unless otherwise stated in a credit line to the data. 
(Continued from previous page)

Conclusions: Our findings support complementary and partly overlapping scavenging and immune functions of LSECs and KCs. This highlights the importance of including LSECs in studies of liver immunity, and liver clearance and toxicity of large molecule drugs and nano-formulations.

Keywords: Sprague Dawley rat, Sinusoidal endothelial cells, Kupffer cells, Macrophages, Transcriptomics, Proteomics, Immune functions, cell markers, Scavenger receptors

\section{Background}

The liver has a central role in host defense [1, 2]. Its extensive capillary network, the sinusoids, houses the body's most effective scavenger cell system comprising the Kupffer cells (KCs; the body's largest reservoir of resident macrophages [3]), and liver sinusoidal endothelial cells (LSECs). For decades KCs, facing the sinusoidal lumen, were believed to be the only liver cell responsible for the clearance of blood-borne material [4, 5]. This view was challenged by a series of studies throughout the 1980 s and 1990s showing that a number of physiological macromolecules and colloids were cleared chiefly by LSECs, but only to a minor extent by KCs [6-15]. Today it is accepted that LSECs and KCs together make up the hepatic "dual cell principle of waste clearance", with LSECs being geared to effective clathrin-mediated endocytosis of nanoparticles $(<200 \mathrm{~nm})$, colloids, and macromolecules, and KCs taking up larger material [5]. The discovery that these cells share the task of blood clearance in this way suggested that LSECs are a highly specialized endothelium with characteristics in common with KCs, not only functionally, but at the molecular level as well. The present study was undertaken to study the similarities and differences of the two cells, by comparing their transcriptomes and proteomes.

The liver receives approximately $25 \%$ of cardiac output, exposing the sinusoidal cells to large volumes of blood, thus placing these cells in a unique position to monitor blood content. Approximately $80 \%$ of the organ blood supply drains the gut and contains (in addition to nutrients) toxins, bacterial components, viruses, and various waste products that are efficiently removed from blood by uptake in LSECs and KCs $[5,15]$, thus preventing deposition and deleterious effects of such components elsewhere. LSECs show an extraordinarily high capacity for uptake of soluble macromolecules and nanoparticles, including virus [10, 11, 15-23]. For this purpose, LSECs express several high affinity endocytosis receptors, some of which are pattern recognition receptors. These include the scavenger receptors (SRs) stabilin-1 and stabilin-2 [24, 25], the macrophage mannose receptor (CD206) [17], and the endocytic Fcgamma receptor IIb2 (FcyRIIb2, CD32b) [26]. In addition, LSECs express several Toll-like receptors (TLRs) [27-29], and in mice, the cells are reported to possess adaptive immune functions, including crosspresentation of endocytosed antigens to naïve $\mathrm{CD}^{+} \mathrm{T}$ cells contributing to the generation of memory $\mathrm{T}$-cells important for liver immune tolerance [1, 27, 30-32]. In contrast to KCs, LSECs are normally not phagocytic but can take up $1 \mu \mathrm{m}$ particles if KCs are depleted [33].

Due to the overlapping functions of LSECs and KCs as scavenger cells $[1,2,5]$, the large endothelial cell diversity between different vascular beds [34, 35], and the lack of standardized methods for LSEC isolation and identification between different research groups [36, 37], LSECs have been described as a cell of controversial and confusing identity [37]. For instance, the pan-leukocyte marker CD45 is often used as a negative selection criterion for isolation of mouse and human LSECs by immune based methods but is reported to be expressed in rat LSECs [36, 38]. Furthermore, LSECs rapidly dedifferentiate in culture $[39,40]$, which poses a problem for longterm co-cultures with e.g. lymphocytes in immune assays. This highlights the importance of using early primary cells when exploring cell functions and molecular expression patterns, and mapping LSEC and $\mathrm{KC}$ gene and protein expression in different species used in biomedical research.

In order to resolve some of the discrepancies in the literature regarding LSEC and $\mathrm{KC}$ markers and molecular phenotypes, we directly compared the transcriptome and proteome of freshly isolated rat LSECs and KCs. Studies comparing the gene/protein expression of LSECs and $\mathrm{KCs}$ are rare. To the best of our knowledge only two studies, both done in $\mathrm{C} 57 \mathrm{Bl} / 6$ mice, have compared the proteome of liver resident cell populations [41, 42], but without discussing LSEC scavenger or immune functions. Our study represents the first comprehensive multiomics profiling and comparison of rat KCs and LSECs. Based on our findings we conclude that LSECs differ from other types of endothelial cells due to their distinct immunological features.

\section{Results}

Isolation of LSECs and KCs using SE-1 and CD11b/c yields highly pure cell preparations

An overview of the transcriptomics and proteomics experiments and purity tests of cells used in the experiments is given in Fig. 1. LSECs and KCs were purified 


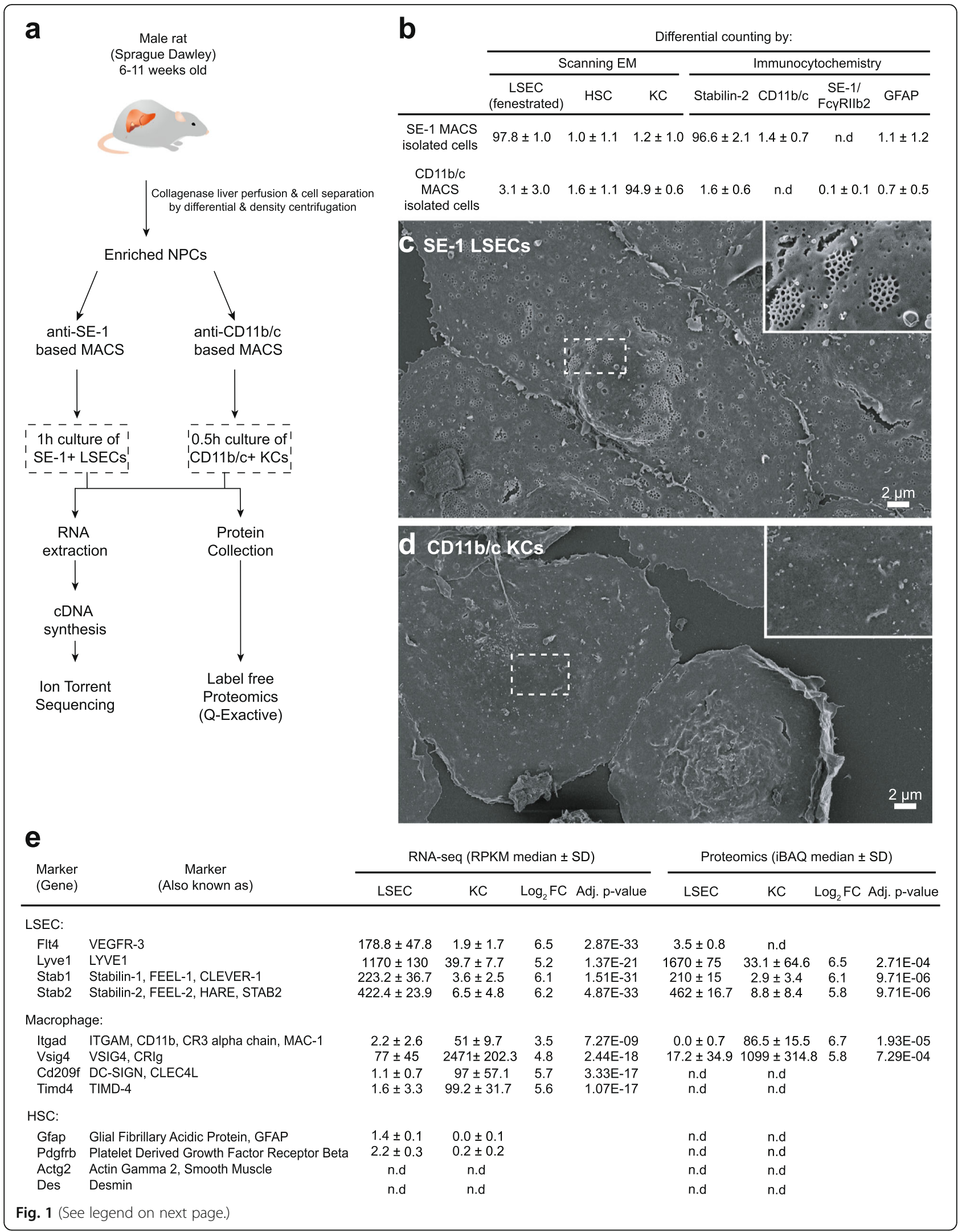


(See figure on previous page.)

Fig. 1 Overview of experimental workflows and cell purity tests. a. Schematic overview of the high-throughput transcriptomics and label-free proteomics workflows. $\mathbf{b}$. Purity of SE-1-MACS-isolated liver sinusoidal endothelial cells (LSECS) and CD11b/c-MACS-isolated Kupffer cells (KCS). Cell isolates were analyzed by scanning electron microscopy (EM) (LSECs: $n=6$, including all cell isolates for proteomics and RNA sequencing; KCs: $n=4$, including all isolates for proteomics), and immune cytochemistry (KC: $n=4$, LSEC: $n=3$, including all cell isolates for proteomics). Results are presented as \% of total cell count (mean \pm standard deviation). Antibodies (Table 1) targeted either stabilin-2 (LSEC marker), SE-1/FcyRllb2 (LSEC marker), CD11b/c (KC marker), or glial fibrillar acidic protein (GFAP, stellate cell marker). N.d., not determined. c-d. Scanning electron micrographs showing the typical morphology of MACS-isolated cells. Insert in c shows LSEC fenestrations (hallmark of LSECS), which were absent in KCs (d). e. Expression level of marker genes for LSECs, KCs, and hepatic stellate cells (HSC) in the KC and LSEC transcriptomes and proteomes. Expression values are given as RPKM (RNA-seq), and iBAQ (label-free proteomics), as described in Methods

by magnetic-activated cell separation (MACS) of nonparenchymal liver cell (NPC) suspensions generated from collagenase perfused rat liver, then plated for $0.5 \mathrm{~h}$ (KCs) or $1 \mathrm{~h}$ (LSECs) and washed with medium before RNA and protein extraction (Fig. 1a). For LSEC, we used the SE-1 monoclonal antibody [43, 44] (Table 1), which targets FcyRIIb2 [45] and has been previously tested for
MACS-based purification of rat LSECs [43]. The isolated cells were > 97\% LSECs (i.e. fenestrated endothelial cells), as examined by scanning electron microscopy (SEM), and $96.6 \%$ were stabilin- 2 positive by immune staining (Fig. 1b-d). The few contaminating cells were $\mathrm{KCs}$ and stellate cells. A monoclonal antibody to CD11b/c (Table $1)$, targeting complement receptor 3 (CR3) was used to

Table 1 Antibodies used in the study

\begin{tabular}{|c|c|c|c|c|}
\hline Antibody (clone) & Target & $\begin{array}{l}\text { Company/ } \\
\text { Reference }\end{array}$ & Catalog \# & $\begin{array}{l}\text { Working } \\
\text { concentration }\end{array}$ \\
\hline \multicolumn{5}{|c|}{ Flow cytometry antibodies and isotype controls } \\
\hline CD45-PE (OX-1) & CD45, PTPRC & Novus Biologicals & NB100-64895PE & $0.85 \mu \mathrm{g} /$ million cells \\
\hline PE Mouse IgG1 & $\operatorname{lgG} 1 \mathrm{k}$ isotype control & BD Pharmingen & 555749 & $0.2 \mu \mathrm{g} /$ million cells \\
\hline HSEC antibody (SE-1) -AF488 & CD32b, FcyRllb2 & Novus Biologicals & $\begin{array}{l}\text { NB110- } \\
\text { 68095AF488 }\end{array}$ & $1 \mu \mathrm{g} /$ million cells \\
\hline Mouse lgG2a AF488 (MG2a-53) & IgG2a k isotype control & Novus Biologicals & NB600-986AF488 & $0.65 \mu \mathrm{g} /$ million cells \\
\hline CD31-eFluor 660 (TLD-3A12) & CD31, PECAM-1 & eBioscience & 50-0310-82 & $0.2 \mu \mathrm{g} /$ million cells \\
\hline $\begin{array}{l}\text { Mouse IgG1k- eFluor } 660 \\
\text { (P3.6.2.8.1) }\end{array}$ & $\operatorname{lgG1} \mathrm{k}$ isotype control & eBioscience & $50-4714$ & $0.2 \mu \mathrm{g} /$ million cells \\
\hline \multicolumn{5}{|l|}{ Immune staining of cells and tissues } \\
\hline HSEC $^{\mathrm{a}}$ antibody (SE-1) & CD32b, FcyRllb2 & Novus Biologicals & NB110-68095 & $10 \mu \mathrm{g} / \mathrm{ml}$ \\
\hline CD11b/c Biotin (OX-42) & CD11b/c, CR3 & Cedarlane & CL042B & $2 \mu \mathrm{g} / \mathrm{ml}$ \\
\hline CD163 (ED2) & CD163 & AbD Serotec & MCA342GA & $10 \mu \mathrm{g} / \mathrm{ml}$ \\
\hline CD68 (ED-1) & CD68 antigen, macrosialin & Abcam & ab31630 & $20 \mu \mathrm{g} / \mathrm{ml}$ \\
\hline GFAP & Glial fibrillary acidic protein & Dako & Z0334 & $15 \mu \mathrm{g} / \mathrm{ml}$ \\
\hline Human MMR/CD206 & $\begin{array}{l}\text { CD206, macrophage mannose } \\
\text { receptor }\end{array}$ & R\&D Systems & AF2534 & $2 \mu \mathrm{g} / \mathrm{ml}$ \\
\hline SR-A1/MSR & Macrophage scavenger receptor $\mathrm{A} 1$ & Novus Biologicals & NBP1-00092 & $12 \mu \mathrm{g} / \mathrm{ml}$ \\
\hline SR-B1 & Scavenger receptor B1 & Novus Biologicals & NB400-104 & $10 \mu \mathrm{g} / \mathrm{ml}$ \\
\hline Rabbit anti-rat HA/SR serum ${ }^{b}$ & Stabilin-2, STAB2 & (24) & & $1: 200$ \\
\hline CD45 (OX-1) & CD45, PTPRC & Novus Biologicals & NB100-64895 & $10 \mu \mathrm{g} / \mathrm{ml}$ \\
\hline CD31 (TLD-3A12) & CD31, PECAM-1 & Invitrogen & MA1-81051 & $10 \mu \mathrm{g} / \mathrm{ml}$ \\
\hline \multicolumn{5}{|l|}{ Magnetic-activated cell sorting } \\
\hline HSEC antibody (SE-1) & CD32b, FcyRllb2 & Novus Biologicals & NB110-68095 & $0.2 \mu \mathrm{g} / \mathrm{million} \mathrm{NPCs}$ \\
\hline CD11b/c Biotin (OX-42) & CD11b/c, CR3 & Cedarlane & CL042B & $0.1 \mu \mathrm{g} / \mathrm{million} \mathrm{NPCs}$ \\
\hline Anti-Mouse lgG2a + b MicroBeads & $\lg G 2 a+b$ & Miltenyi & 130-047-201 & $2 \mu \mathrm{l} /$ million NPCs \\
\hline
\end{tabular}

${ }^{\mathrm{a}} \mathrm{HSEC}$, hepatic sinusoidal endothelial cell

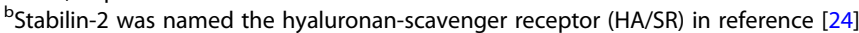

Secondary antibodies used for immune labeling of cells and tissues were all species-matched AlexaFluor antibodies from Invitrogen (ThermFischer) 
purify KCs. This yielded $94.9 \% \mathrm{KCs}$ - contaminating cells were 3.1\% LSECs and 1.6\% stellate cells (Fig. 1b).

Quantitative expression of marker genes used for cross validation of the transcriptomics and proteomics data are listed in Fig. 1e. Consistent with SEM and immunocytochemistry analysis of MACS-isolated cells, expression of macrophage and stellate cell markers were low in the LSEC transcriptomes and proteomes, whereas expression of LSEC and stellate cell markers were low in the $\mathrm{KC}$ transcriptomes and proteomes.

To check the hepatic intralobular distribution of cells expressing SE-1 (i.e. FcyRIIb2), and CD11b/c, frozen rat liver sections were stained with the same antibodies used for MACS-isolation of cells (Fig. 2). The SE-1 antibody showed a strict sinusoidal staining pattern, colocalizing with the LSEC marker stabilin-2 $[24,46,47]$ in all sinusoids (Fig. 2a, b). Most CD11b/c positive cells were located in the periportal region and showed a different staining pattern than stabilin-2 (Fig. 2c).

\section{Global information generated from omics data profiling} In the RNA-seq experiment 10,306 genome features were deemed expressed and included in the subsequent analyses, while in the label-free proteomics experiment 2996 non-redundant protein IDs were deemed expressed and included in the further analyses. Principal component analysis (Fig. 3a) segregated the LSEC and KC samples into disparate clusters coherent with the distinct biology of the cells.

Figure $3 \mathrm{~b}$ illustrates the total number of gene products identified with the respective techniques, and their overlap, in the LSEC and KC groups. The proteome covered $26-27 \%$ of the transcriptome. Notably, most proteins (90.8-91.5\%) identified in the proteome had valid

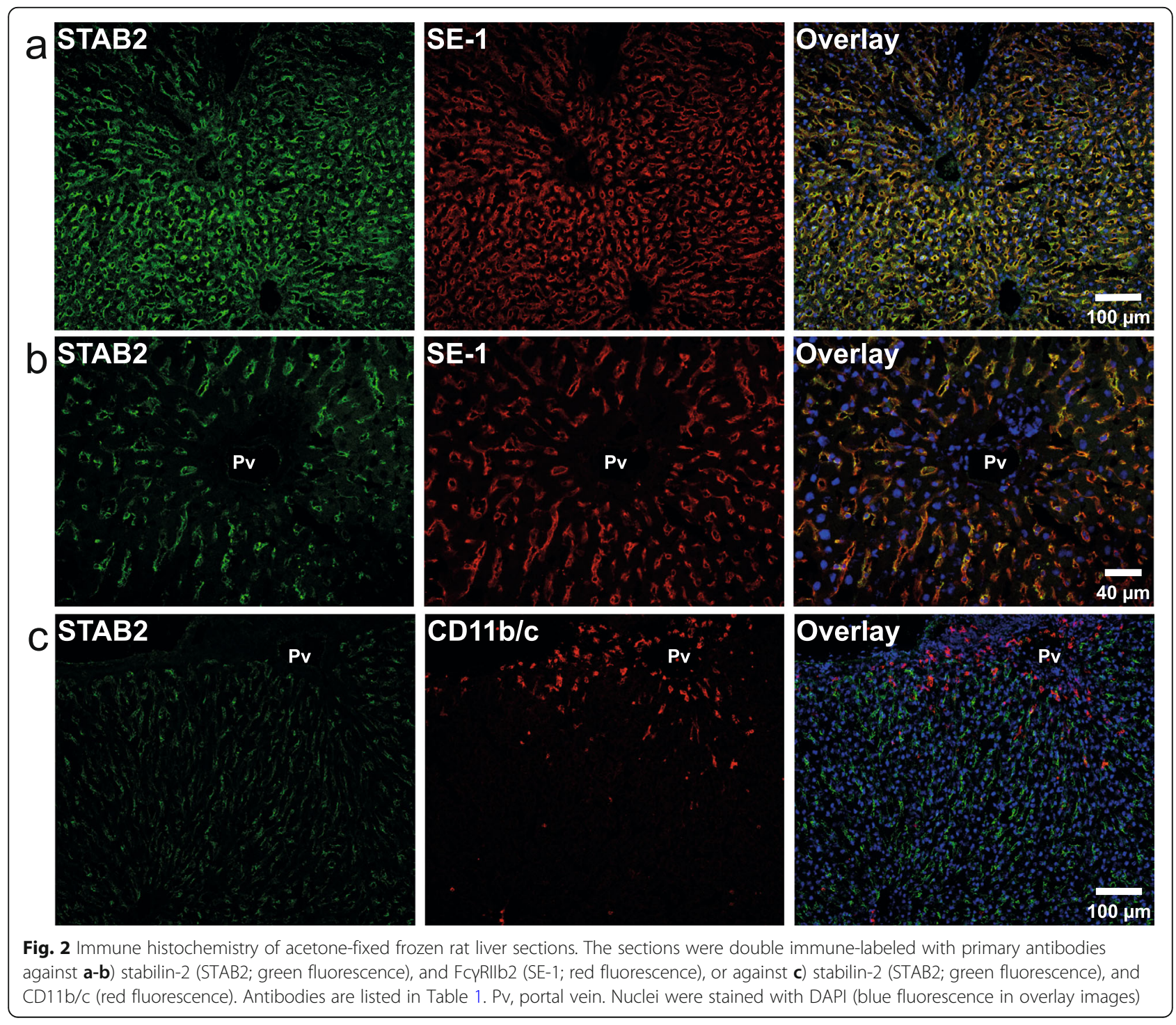




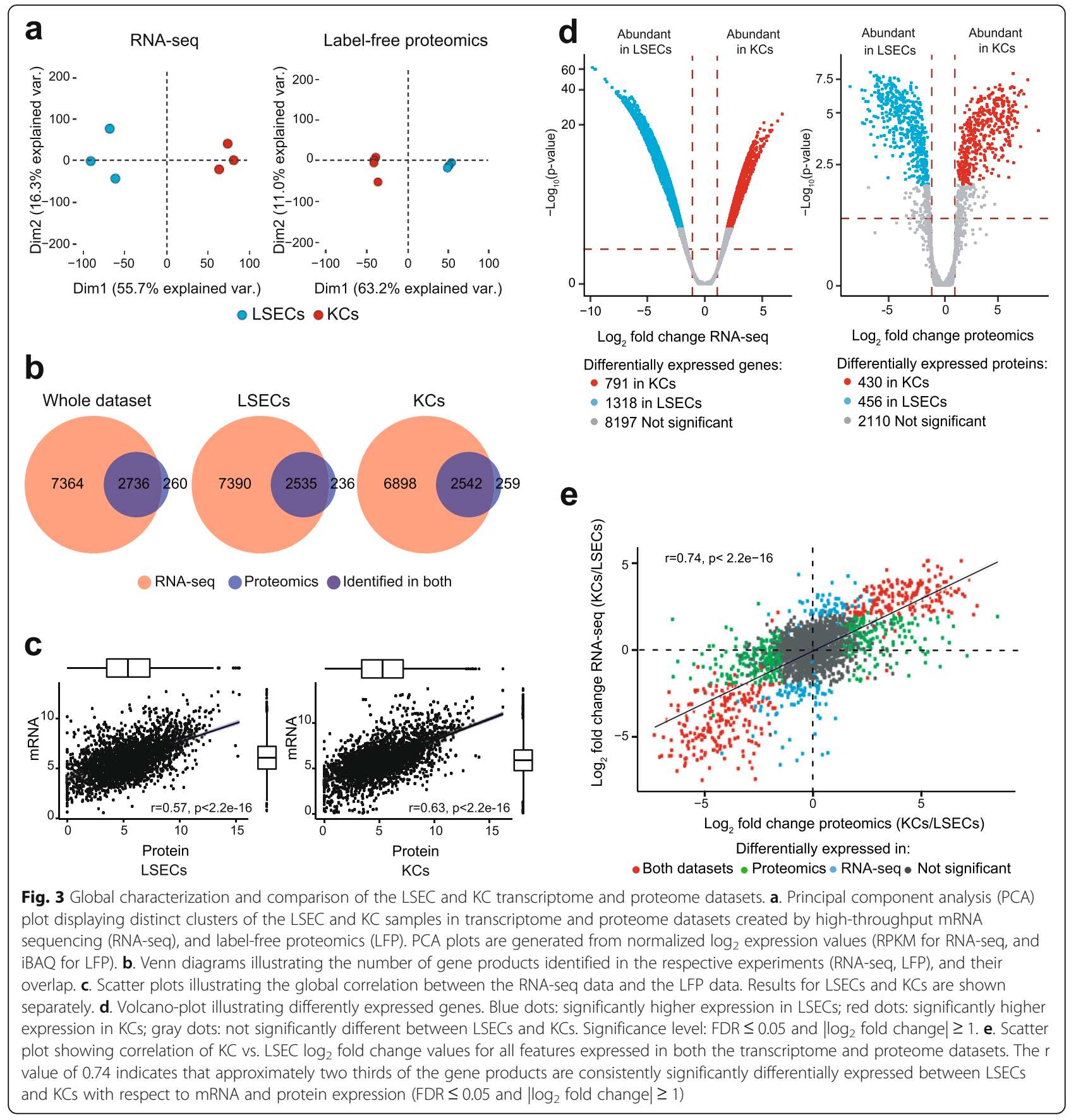

corresponding mRNA in the transcriptome. To evaluate the coherence between the transcriptome and proteome, we calculated the global Pearson correlation coefficient $r$ using the expression data between the omics datasets for each cell type. The global correlation $\mathrm{r}$ value was 0.57 for LSECs, and 0.63 for KCs (Fig. 3c) which are in the upper end of the previously reported range of 0.4-0.6 $[41,48]$ supporting the reliability of the data.

Differentially expressed gene products are key to understanding phenotypic and functional variation between cell types. The results of the differential expression analyses of the RNA-seq data, and the proteomics data are summarized in Fig. 3d. We identified 2109 gene products in the transcriptome (20.5\%) as significantly differentially expressed (with cutoff of FDR (false discovery rate) $\leq 0.05$ and $\mid \log _{2}$ fold change $\left.\mid \geq 1\right)$ in LSECs and KCs. Similarly, in the proteome, 886 proteins $(\sim 30 \%)$ were significantly differently expressed in the two cells (with cutoff of FDR $\leq 0.05$ and $\mid \log _{2}$ fold change $\mid \geq 1$ ). Despite differences in percentage of differentially 
expressed gene products in the RNA-seq and proteomics experiments, the $\log _{2}$ fold changes for the unique gene products identified in both datasets showed high correlation ( $\mathrm{r}=0.74$ [95\% CI: 0.72-0.75]) (Fig. 3e), suggesting good congruence between the two techniques.

\section{LSECs and KCs show enrichment of terms reflecting their ontogeny}

We used ranked gene lists based on expression level from the RNA-seq experiment as input for gene set enrichment analysis (GSEA) $[49,50]$ to identify the intrinsic functional characteristics of LSECs and KCs. GSEA showed enrichment of 268 biological processes in LSECs and 121 biological processes in KCs with FDR q-value $\leq 0.05$ corresponding to Gene Ontology (GO) terms [51, 52] in the Molecular Signatures Database $[49,53]$ that concur with the generic role of these cells (Additional file 1; Fig. 4). Like other endothelial cells, LSECs are involved in development, morphogenesis, patterning and maintenance of blood vessels, and displayed enrichment of gene sets associated with response to vascular endothelial growth factor and regulation of WNT, BMP, and TGF $\beta$ signalling pathways. KCs, being macrophages, displayed enrichment of terms related to adaptive and innate immune responses.

Expression of genes associated with endocytic function, cytoskeleton organization, and positive regulators of endocytosis, such as 1-phosphatidylinositol-4-phosphate 5-kinase (Pip5klc), phospholipase D1/2 (Pld2), integrin subunit beta1 (Itgb1), GTPase Hras, clathrin adaptor protein (Dab2), caveolin1 (Cav1), and E3 ligase NEDD4 (Nedd4) were higher in LSECs than in KCs (Additional file 2). Moreover, LSECs showed higher expression of transport-related proteins such as $\mathrm{EH}$ domain-containing protein 3 (Ehd3), which is suggested to be involved in transport of stabilin-1-positive vesicles [39], adaptor-related protein complex 1 beta 1 subunit (Ap1b1), and sorting nexin (Snx) 8 and 33, which are associated with vesicular transport (Additional file 2). Interestingly, RNA-seq of LSECs revealed high expression of genes coding for connective tissue components such as Sparc, Col4a1, Col4a2, Egfl7, and Mfge8, indicating a significant role of these cells in extracellular matrix maintenance and remodeling of liver (Additional file 2). Transcription factor Gata4, which is essential for LSEC differentiation $[39,47]$ was specifically expressed in the LSEC transcriptome (Additional file 2).

\section{Most gene products involved in KC immune functions are also expressed in LSECs}

Genes associated with the term immune system processes (GO:0002376) include 2645 annotated objects in the rat genome database (December 13, 2019). Of these, we found 1466 expressed genes in the RNA-seq data, and 554 expressed genes in the label-free proteomics experiments that were associated with the term (Fig. 5a; Additional file 3). Both cells expressed numerous immune genes - the majority of which were expressed at low density but more abundant in KCs compared to LSECs. To ascertain the immunological role of expressed genes we performed functional enrichment analysis (DAVID $6.8[54,55])$ of genes with expression values $\geq 10$ RPKM (reads per kilobase of exon model per million mapped reads [56]) separately in the LSEC and KC RNA-seq datasets. The threshold 10 RPKM was set to increase the confidence of the results. The immune terms that were significantly enriched $(F D R \leq 0.05)$ in $\mathrm{KC}$ and LSEC transcriptomes were similar, and each term contained almost similar number of expressed genes in the two cells (Fig. 5b).

\section{Both cell types show high expression of scavenger receptors and immune lectins}

LSECs and KCs express a variety of SRs, C-type lectins, and TLRs [16, 17, 27-29]. We found that both cells expressed many SRs and immune lectin gene products at high densities, of which some were cell type specific (Fig. 6a; Additional file 4), providing the capacity of rapid sensing and clearance of various danger molecules. Among these were the macrophage mannose receptor (Mrc1) and macrophage SR-A1 (Msr1) which were abundantly expressed both in the LSEC and KC transcriptomes and proteomes (Fig. 6a) and confirmed by immune cytochemistry (Fig. 6c). The high-density lipoprotein receptor SR-B1 (Scarb1) was also equally expressed in the rat LSEC and KC transcriptomes, but at low density, and were not identified in the cell proteomes. However, immune labelling experiments validated SR-B1 protein expression in both LSECs and KCs (Fig. 6c), in accordance with [57]. Of note, CD36, a reliable LSEC marker in human liver [58] was evidently expressed in rat KCs but was very low in rat LSECs (Fig. 6a). Same receptor was previously reported to be absent from Sprague Dawley rat LSECs in western blot and immune fluorescence experiments [59].

Stabilin-1 (Stab1) and stabilin-2 (Stab2) were expressed at much higher densities in the LSECs than in KCs (Fig. 6a-b). Immune labeling of NPCs (Fig. 6c) and frozen rat liver sections (Fig. 2) for stabilin-2 confirmed LSEC specific expression and a typical LSEC distribution pattern in all hepatic zones of this protein, in accordance with [60] supporting the use of stabilin-2 as a specific pan-LSEC marker. Furthermore, rat LSECs showed high mRNA and protein expression of Clec4g (LSECtin) and Clec4m (DC-SIGNR) (Fig. 6a, b), as was also reported in a study of human LSECs [61], where Clec4g was used as a specific LSEC marker in liver single cell transcriptome studies [62]. 


\begin{tabular}{|c|c|c|c|}
\hline \multirow{2}{*}{\multicolumn{2}{|c|}{ GO biological processes }} & Q-value & Number of genes \\
\hline & & $\begin{array}{lllll}0.0 & 0.01 & 0.02 & 0.03 & 0.04\end{array}$ & $100 \bullet 200 \bullet 300 \bullet 400 \bullet$ \\
\hline \multirow{13}{*}{ 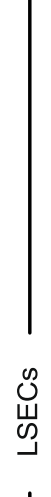 } & \multirow{2}{*}{\multicolumn{3}{|c|}{ 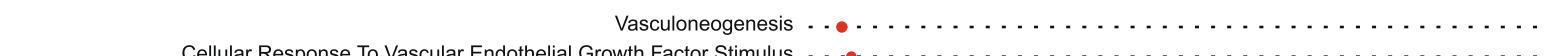 }} \\
\hline & & \multicolumn{2}{|c|}{ Cellular Response To Vascular Endothelial Growth Factor Stimulus . . - } \\
\hline & \multicolumn{3}{|l|}{$\begin{array}{r}\text { Endothelium Development } \cdots \\
\text { Blood Vessel Morphogenesis } \ldots\end{array}$} \\
\hline & $\begin{array}{l}\text { Blood Vessel Morphogenesis } \\
\text { Sprouting Angiogenesis }\end{array}$ & $\cdots 0 . . . . .$. & 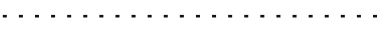 \\
\hline & & $\cdots \cdots \cdots \cdots \cdots$ & $\cdots \cdots \cdots \cdots \cdots$ \\
\hline & \multicolumn{3}{|c|}{$\begin{array}{r}\text { Pattern Specification Process } \ldots . . \\
\text { Hippo Signaling } \ldots .\end{array}$} \\
\hline & \multicolumn{3}{|l|}{ Cell Cell Junction Organization $\ldots$} \\
\hline & \multicolumn{3}{|l|}{$\begin{array}{r}\text { Regulation Of Cellular Response To Transforming Growth Factor Beta Stimulus } \cdots \\
\qquad \text { Connective Tissue Development } \ldots\end{array}$} \\
\hline & Regulation Of Bmp Signaling Pathway & ......... & \\
\hline & \multicolumn{3}{|c|}{ Response To Transforming Growth Factor Beta .... } \\
\hline & \multicolumn{3}{|c|}{$\begin{array}{r}\text { Cell Junction Organization } \ldots \ldots \\
\text { Regulation Of Vascular Permeability }\end{array} \ldots \ldots \ldots \ldots$} \\
\hline & \multicolumn{3}{|c|}{ 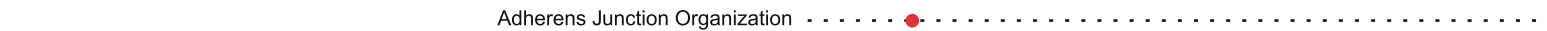 } \\
\hline & \multicolumn{3}{|l|}{$\begin{array}{r}\text { Branching Involved In Blood Vessel Morphogenesis } \cdots \\
\text { Notch Signaling Pathway } \cdots\end{array}$} \\
\hline \multicolumn{4}{|c|}{ 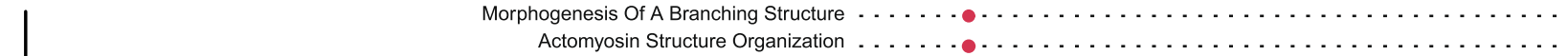 } \\
\hline \multicolumn{4}{|c|}{$\begin{array}{l}\text { Establishment Of Endothelial Barrier } \cdots \\
\text { Transforming Growth Factor Beta Receptor Signaling Pathway }\end{array}$} \\
\hline \multicolumn{4}{|c|}{ Response To Bmp ... } \\
\hline \multicolumn{4}{|c|}{$\begin{array}{l}\qquad \text { Cell Substrate Adhesion } \ldots \\
\text { Cell Surface Receptor Signaling Pathway Involved In Cell Cell Signaling } \ldots\end{array}$} \\
\hline \multicolumn{4}{|c|}{ Cell Cell Signaling By Wnt .. } \\
\hline \multicolumn{4}{|c|}{$\begin{array}{l}\text { Canonical Wnt Signaling Pathway } \\
\text { Vascular Endothelial Growth Factor Receptor Signaling Pathway }\end{array}$} \\
\hline & $\begin{array}{r}\text { Homophilic Cell Adhesion Via Plasma Membrane Adhesion Molecules } \\
\text { Vascular Process In Circulatory System }\end{array}$ & $\cdots \cdots$ & \\
\hline & Blood Vessel Remodeling & $\ldots \ldots \ldots \ldots$ & $\ldots \ldots \ldots$. \\
\hline T & Cell Activation Involved In Immune Response & $\ldots \ldots \ldots \ldots$ & 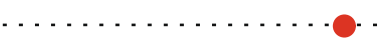 \\
\hline & Myeloid Leukocyte Activation & .. & \\
\hline & Regulation Of Humoral Immune Response & - & •. \\
\hline & Production Of Molecular Mediator Involved In Inflammatory Response & .. & -. \\
\hline & Regulation Of $\mathrm{Ph}$ & $\ldots \ldots \ldots \ldots \ldots$ & $\ldots \ldots \ldots \ldots \ldots \ldots \ldots$ \\
\hline & Regulation Of Phagocytosis & $\cdots \ldots \ldots \ldots \ldots$ & $\ldots \ldots \ldots \ldots \ldots \ldots$ \\
\hline & Adaptive Immune Response & $\cdots \ldots \ldots \ldots \ldots$. & $\ldots \ldots \ldots \ldots \ldots \ldots$ \\
\hline & Interleukin 6 Production & -. & $\cdots$ \\
\hline & Myd88 Dependent Toll Like Receptor Signaling Pathway & $\ldots .$. & 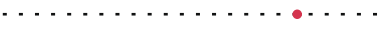 \\
\hline & Interferon Gamma Production & $\cdots$ & $\cdots \cdots$ \\
\hline & Regulation Of Leukocyte Mediated Immunity & $\ldots \ldots \ldots \ldots \ldots \ldots$ & $\ldots \ldots \ldots \ldots \ldots \ldots, \bullet$ \\
\hline & Leukocyte Activation Involved In Inflammatory Response & $\cdots \ldots \ldots \ldots \ldots$ & $\ldots \ldots \ldots \ldots \ldots \ldots \ldots$ \\
\hline & Lymphocyte Activation & $\cdots$ & $\cdots \cdot \cdots$ \\
\hline O্ & Respiratory Burst & $\ldots \ldots \ldots \ldots \ldots$ & $\ldots \ldots \ldots \ldots \ldots \ldots \ldots$ \\
\hline & Phagocytosis & $\cdots \ldots \ldots \ldots \ldots$ & $\cdots \ldots \ldots \ldots \ldots+\cdots$ \\
\hline & Cellular Response To Lipoprotein Particle Stimulus & $\cdots \ldots \ldots \ldots \ldots$ & $\ldots \ldots \ldots \ldots \ldots \ldots \ldots$ \\
\hline & Defense Response To Bacterium & $\ldots \ldots \ldots \ldots \ldots$ & $\ldots \ldots \ldots \ldots \ldots \ldots$ \\
\hline & Regulation Of Immune Effector Process & .. & $\ldots \ldots \ldots \ldots \ldots$ \\
\hline & Transferrin Transport & $\cdots \ldots \ldots \ldots$ & $\cdots \ldots \ldots \ldots \ldots \ldots \ldots$ \\
\hline & Phagosome Acidification & . & \\
\hline & Activation Of Immune Response & $\ldots \ldots \ldots \ldots$ & $\cdots \ldots \ldots \ldots$ \\
\hline & Lymphocyte Differentiation & (1) & $\cdots \cdot \cdots$ \\
\hline & Antigen Receptor Mediated Signaling Pathway & $\ldots \ldots \ldots \ldots \ldots$ & $\ldots \ldots \ldots \ldots \ldots$ \\
\hline & Immune Response Regulating Cell Surface Receptor Signaling Pathway & $\cdots \ldots \ldots \ldots \ldots$ & 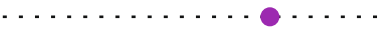 \\
\hline & Complement Activation & $\cdots \ldots \ldots$ & $\cdots \cdot \cdot$ \\
\hline & Cytokine Secretion & 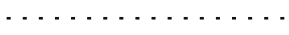 & 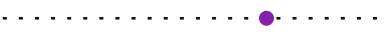 \\
\hline & Antigen Processing And Presentation Of Exogenous Peptide Antigen Via Mhc Class I & $\cdots \cdots \cdots \cdots$ & $\cdot \bullet \cdot$ \\
\hline$\perp$ & Lytic Vacuole Organization & $\cdots \ldots \ldots \ldots \ldots$ & $\cdots \ldots \ldots \ldots$ \\
\hline & & -1 & 1 \\
\hline & & Normalized & hment Score (KCs/LSECs) \\
\hline & legend on next page.) & & \\
\hline
\end{tabular}


(See figure on previous page.)

Fig. 4 Dot plot showing selected enriched terms in KC and LSEC transcriptomes, belonging to GO biological processes in the Molecular Signatures Database (MSigDB) [53]. The Normalized Enrichment Score reflects the degree of overrepresentation of the genes in a gene set across the entire ranked list of genes after adjusting for differences in gene set size, and correlation between the gene sets and the RNA-seq expression data. Dot size represents the number of genes assigned to the specific process, and dot colour represents the associated FDR q-value generated from the GSEA analysis

Some of the receptors reported in the literature to discriminate $\mathrm{KCs}$ from other liver cells, were also expressed in the LSEC transcriptome. These included Marco, Cd5l, Clec4f, Cd163, lgals3, and Cd68 (Fig. 6a, b). However, their transcript level in $\mathrm{KCs}$ were significantly higher compared to LSECs, and their abundance in the LSEC proteome was low. Immune labeling of NPCs for CD163 (not shown) and CD68 showed staining of KCs only (Fig. 6c) and labeling of rat liver sections for CD68 together with the LSEC marker stabilin-2 showed a staining pattern of CD68 that is typical for KCs (Additional file 5), supporting the proteomic results.

Several TLRs were detected in LSECs and KCs transcriptomes (Additional file 3). The abundance of Tlr4, 5, $6,7,8,10,11$, and 12 mRNA was significantly higher $(F D R \leq 0.05)$ in $K C s$, whereas Tlr2, 3, and 13 were not significantly different. The only TLR identified by proteomics at steady state was TLR3 which was identified in both cells.

\section{Immune regulatory factors expressed by LSECs and KCs} When reviewing genes annotated with cytokine receptor binding (GO:0005126), cytokine receptor activity (GO: 0004896), complement activation (GO:0006956), and complement receptor activity (GO:0004875), we identified 209 genes in the transcriptome (out of 551 objects associated under the terms), and 54 proteins in the proteome (Additional file 6). Low protein identification may be due to the fact that these genes are normally expressed at low levels in non-stimulated cells from healthy animals (as analyzed in this study), and many gene products associated with the terms represent secreted proteins, mostly found extracellularly. Thus, the bulk of gene products affiliated with the terms were only detected in the transcriptome, and at low level. Many were also differently expressed in the LSEC and KC transcriptomes (Fig. 7a).

Figure $7 \mathrm{~b}-\mathrm{c}$ reflects the complex cytokine milieu of the sinusoids. LSECs showed significantly higher expression of the cytokine receptors Tgfbr3, Il6st, Osmr, Il1r1 and Lifr (Fig. 7b) enabling them to sense and respond to the cytokines Tgfb3, Osm, Il1b and Lif in paracrine and autocrine manners. Tgfb3, Osm, and Il18 were more abundantly expressed by KCs (Fig. 7c). LSECs also expressed high levels of Ackr3 (Fig. 7b) which is involved in scavenging and degradation of chemokines, thus regulating their levels in the hepatic sinusoids. KCs showed significantly higher expression of the cytokine receptors Il6r and Csf3r, and chemokine receptor Cxcr4 (Fig. 7b), which allow KCs to respond to Ccl24, Cxcl12, $\mathrm{Ccl} 2, \mathrm{Ccl} 6$, and $\mathrm{Ccl} 7$ in an autocrine or paracrine manner (Fig. 7c).

The expression of colony stimulating factor receptors Csf1r, Csf2ra and Csf3r were also higher in KCs (Fig. 7b). Of these, Csf1r and Csf2ra were detected by proteomics, being significantly higher in KCs (Additional file 6). Interaction of colony stimulating factor receptors with their ligands, e.g. Csf1 and Csf2 which were abundantly expressed in LSECs (Fig. 7c), affects KC maturation [63], underlining the importance of LSECs for proper KC function.

The complement system is an important part of the innate immune system. Hepatocytes are major producers of complement proteins, whereas NPCs regulate complement activation [42]. Gene products representing complement receptors (Fig. 7d), and triggers of complement activation (C1qa, C1qb, C1qc; Fig. 7e) were significantly more abundant in the $\mathrm{KC}$ transcriptome and proteome datasets, whereas the expression of the $\mathrm{C} 1$ inhibitors C1qbp and Serping1 was similar in the two cells (detected only in the transcriptome; Fig. 7e).

\section{LSECs express the machinery needed for antigen presentation and lymphocyte activation}

A series of studies in mouse models suggest that LSEC cross-presentation of exogenous soluble antigens to naïve $\mathrm{T}$ cells is central to maintaining liver immune tolerance (reviewed in [1]). However, there are some controversies [37]. As LSECs rapidly dedifferentiate in culture $[39,40]$ and cells are cultured for several days in lymphocyte stimulation experiments, the in vivo contribution of LSECs in adaptive immunity may be difficult to extrapolate from in vitro experiments. There may also be species differences. We therefore investigated the basal expression of gene products associated with antigen processing and presentation (GO:0019882), and lymphocyte co-stimulation (GO:0031294) in rat LSECs and KCs (Additional file 7). The expression of taptransporters, immunoproteases, and lysosomal enzymes involved in processing and intracellular traffic of antigens, were similar in the transcriptomes and proteomes of both cells except for Ctse (cathepsin E) and Ctss 


\section{a}
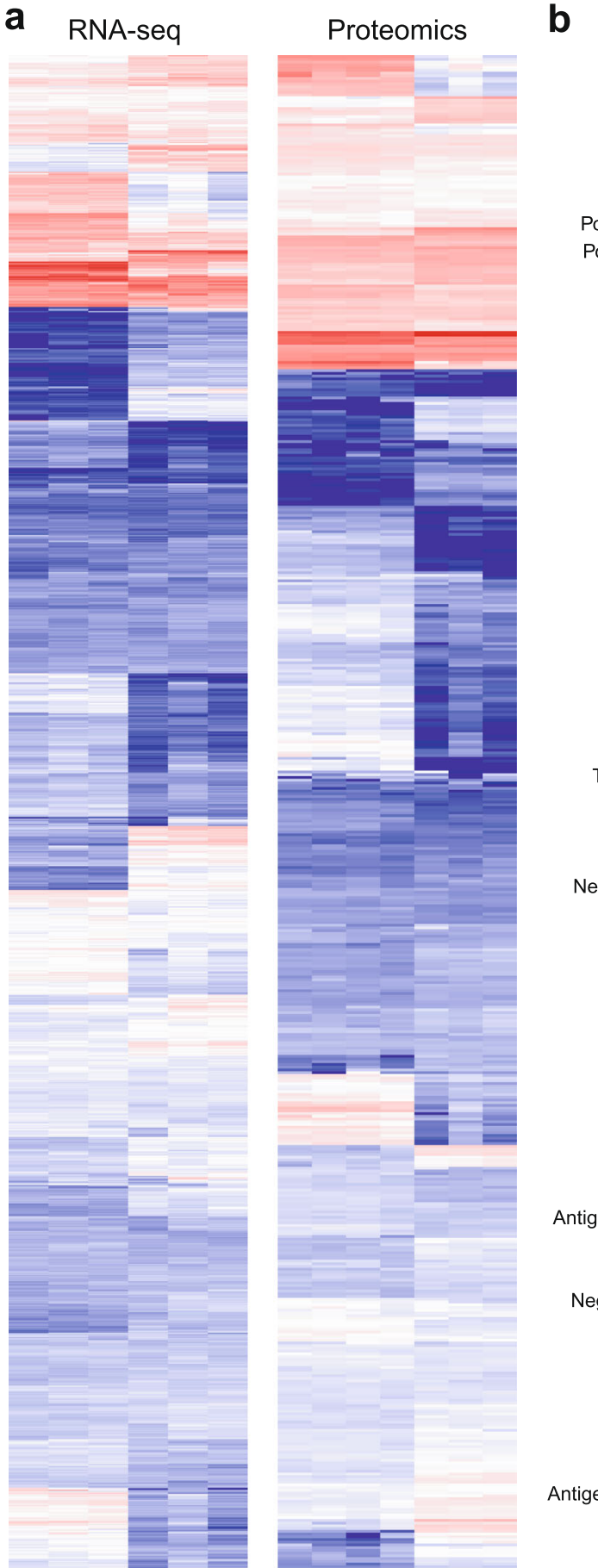
Cellular response to lipopolysaccharide regulation of I-kappaB kinase/NF-kappaB signaling Positive regulation of NF-kappaB transcription factor activity Cell adhesion Response to cytokine Cellular response to tumor necrosis factor Adaptive immune response Response to virus Defense response to Gram-positive bacterium Positive regulation of tumor necrosis factor production Integrin-mediated signaling pathway Response to glucocorticoid Cytokine-mediated signaling pathway Cellular response to interferon-gamma Neutrophil chemotaxis

Antigen processing and presentation Cellular response to interleukin-1 Positive regulation of inflammatory response Lipopolysaccharide-mediated signaling pathway Cellular response to hydrogen peroxide Positive regulation of phagocytosis Transforming growth factor beta receptor signaling pathway

Positive regulation of interferon-gamma production Chemotaxis

Positive regulation of JNK cascade Negative regulation of NF-kappaB transcription factor activity Negative regulation of inflammatory response Response to bacterium

Regulation of inflammatory response I-kappaB kinase/NF-kappaB signaling Cellular response to growth factor stimulus Chemokine-mediated signaling pathway T cell activation Response to interferon-gamma Cellular response to cytokine stimulus Negative regulation of $\mathrm{T}$ cell proliferation Leukocyte cell-cell adhesion Antigen processing and presentation of antigen via $\mathrm{MHC}$ class I Immune system process

Defense response to protozoan Negative regulation of I-kappaB kinase/NF-kappaB signaling Monocyte chemotaxis

Response to tumor necrosis factor Positive regulation of neutrophil chemotaxis

Positive regulation of $\mathrm{T}$ cell activation Immunoglobulin mediated immune response

Myeloid dendritic cell differentiation Antigen processing and presentation of antigen via MHC class II Positive regulation of $\mathrm{T}$ cell migration Positive regulation of interleukin- 6 secretion Cellular response to interferon-alpha Positive regulation of interferon-alpha production Natural killer cell differentiation Response to interferon-beta NIK/NF-kappaB signaling Response to interferon-alpha -
$\begin{array}{llllllll}0 & 2 & 4 & 6 & 8 & 10 & 12 & 14\end{array}$
$\begin{array}{lllllllll}0 & 2 & 4 & 6 & 8 & 10 & 12 & 14 & 16\end{array}$ $\log _{2}(\mathrm{RPKM}+1)$
$\log _{2}(\mathrm{iBAQ}+1)$

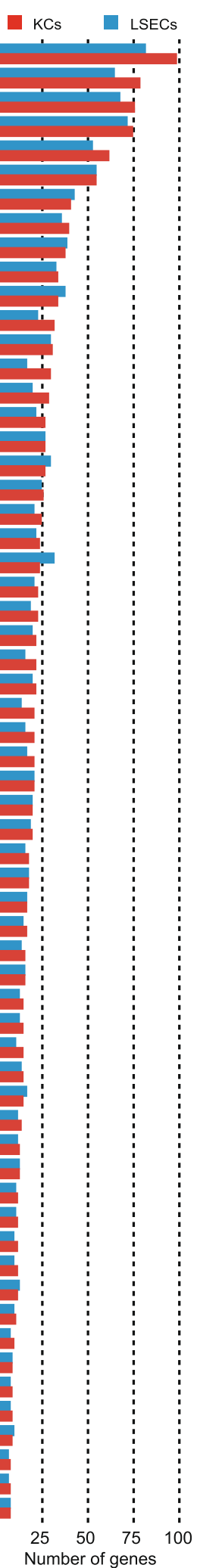

Fig. 5 (See legend on next page.) 
(See figure on previous page.)

Fig. 5 Expression of immune genes in rat LSECs and KCs. a. Unscaled heatmaps of normalized $\log _{2}$ expression values $\left(\log _{2}(R P K M+1)\right.$, and $\log _{2}$ $(\mathrm{BAQ}+1))$ for all gene products associated with the term immune system processes (GO:0002376) in the KC and LSEC transcriptome and proteome. $\mathbf{b}$. The figure shows significantly enriched $\mathrm{GO}$ terms (FDR $\leq 0.05$ ) associated with immune functions, and the density of corresponding genes with expression $\geq 10$ RPKM in the LSEC and KC transcriptomes

(cathepsin S) which were significantly more abundant in the KCs (Fig. 8a-b). Expression of MHC class II genes was detected in both cells, but significantly higher in KCs (Fig. 8c). Concerning co-stimulatory molecules, LSECs expressed significantly higher levels of some gene products involved in activation of $\mathrm{T}$ cells (Cav-1, Dpp4, Cd40, Cd320, and Efnb1), while $\mathrm{KCs}$ showed an abundance of gene products from the B7/CD28 superfamily (Cd80, Cd86, Btla, Icoslg) (Fig. 8d). Btla, Icoslg, and $\mathrm{Cd} 4$ were expressed in both cells, but significantly higher in KCs. BTLA [64], and CD4 [65] are also reported in human LSECs.

\section{A minor subset of rat LSECs expresses the pan leukocyte marker CD45}

CD45 is reported to be widely expressed in rat LSECs, with high expression in periportally located LSECs, and low expression in mid-zonal LSECs $[38,66]$. We here report low expression of CD45 in the LSEC transcriptome, and an even lower expression in the LSEC proteome compared to KCs (Fig. 9a). In order to explore this further, we did flow cytometry of NPCs, and CD45 and stabilin-2 double immune labelling of rat liver sections (Additional file 8). We did not observe a clear colocalization of CD45 with the LSEC marker stabilin-2 in the sinusoids, suggesting either absence or low expression of CD45 in rat LSECs in general or expression in a small subpopulation of these cells. We then performed multicolor flow cytometry (Fig. 9b-f) of rat liver NPCs labeled with antibodies to CD45, SE-1/FcyRIIb2 (specific LSEC marker), and CD31 (pan endothelial cell marker; Additional file 8). NPCs from the $25-45 \%$ Percoll gradient interface were used instead of SE-1-MACS-isolated LSECs to eliminate any selection bias. Using strict gating (Additional file 8), we found that $4.0 \%( \pm 1.06, n=4)$ of small, low complex, live-gated SE-1 ${ }^{+}$cells were $\mathrm{CD} 31^{+} \mathrm{CD} 45^{+}$(Fig. 9g), suggesting expression of CD 45 in a small subpopulation of LSECs.

LSECs from normal liver have been reported to not express CD31on the cell surface [67] but in our flow cytometry experiments (Fig. $9 \mathrm{~g}$ ) this marker was shown to be expressed in $97.4 \%( \pm 1.80, n=4)$ of SE-1 positive cells. Immune staining of liver sections showed positive staining in all vasculature, albeit weaker in LSECs than in other endothelia (Additional file 8).

\section{Discussion}

The liver cells facing the blood are represented almost entirely by KCs and LSECs. These two cells make up the most important clearance system for removal of blood borne macromolecules and particles that are incompatible with blood homeostasis [5]. This avid scavenger activity thus fulfills a central role in liver immunity $[1,2]$ but at the same time poses a serious challenge, namely unwanted uptake of large molecule drug compounds [23]. Curiously, few studies have been undertaken to determine similarities and differences between LSECs and $\mathrm{KCs}$ on gene expression and/or proteome levels. Only two comprehensive studies, both done in the inbred C57Bl/6 mouse, have compared liver resident cell populations at the proteome level $[41,42]$. The study by Azimifar et al. [41] focused on the distinct functional roles of various hepatic cell types in cholesterol flux, cellular trafficking, and growth receptor signaling, whereas Ding et al. [42] presented an integrated omics analysis focusing on communication and co-ordination between hepatocytes and NPCs, in particular KCs. Against this background we found it timely to carry out a highthroughput mRNA transcriptome and proteome expression study of the two types of specialised hepatic scavenger cells in rat, and focus on the analysis of immune function genes. We chose the outbred Sprague Dawley rat to cover a wide number of genotypes. This rat strain has been widely used in LSEC blood clearance and hepatotoxicity studies [16].

Our omics analysis revealed expression of a great number of genes related to immune functions in both cells. As expected in non-stimulated cells, most of these genes were expressed at low density; however, the great number of expressed immune genes supports the central role for both cells in liver immunity. LSECs seem to be unique among endothelial cells in this respect. Nolan et al. [35] used microarray profiling to compare primary microvascular endothelial cells isolated from liver and several other organs in C57BL/6 mice, and found significant heterogeneity between transcriptomes of the different endothelial cell populations. We did DAVID enrichment analysis [54, 55] on the liver specific gene list (Additional file 9) obtained by pairwise comparison of their LSEC gene expression data (GEO public database-Series GSE47067 [35]) with expression data for other organ-specific endothelial cells included in their study, and found enrichment of terms associated with 


\section{a}

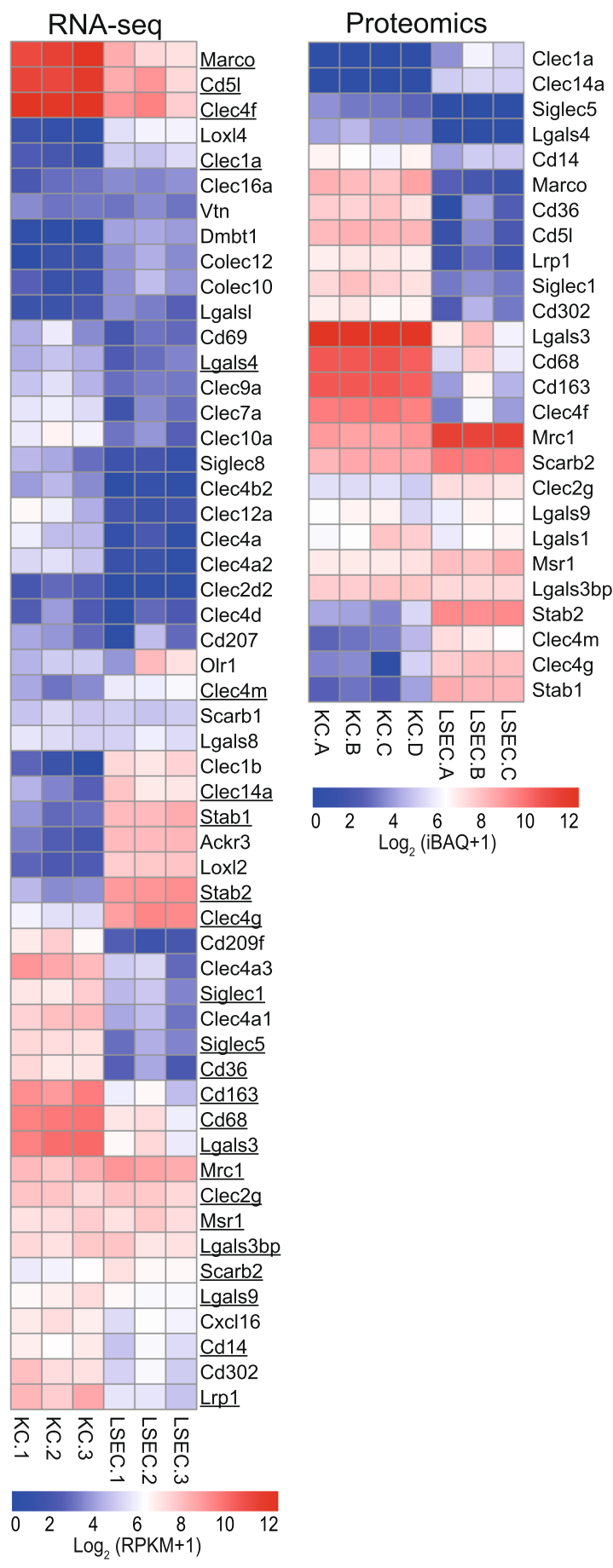

b

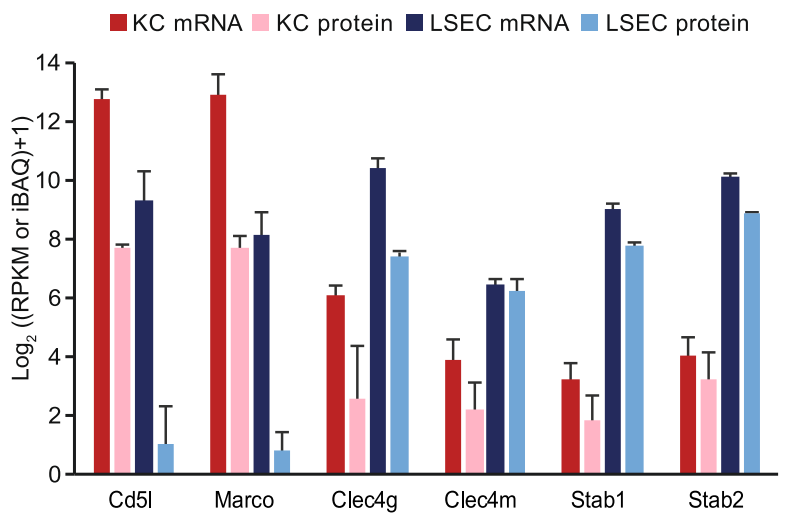

C

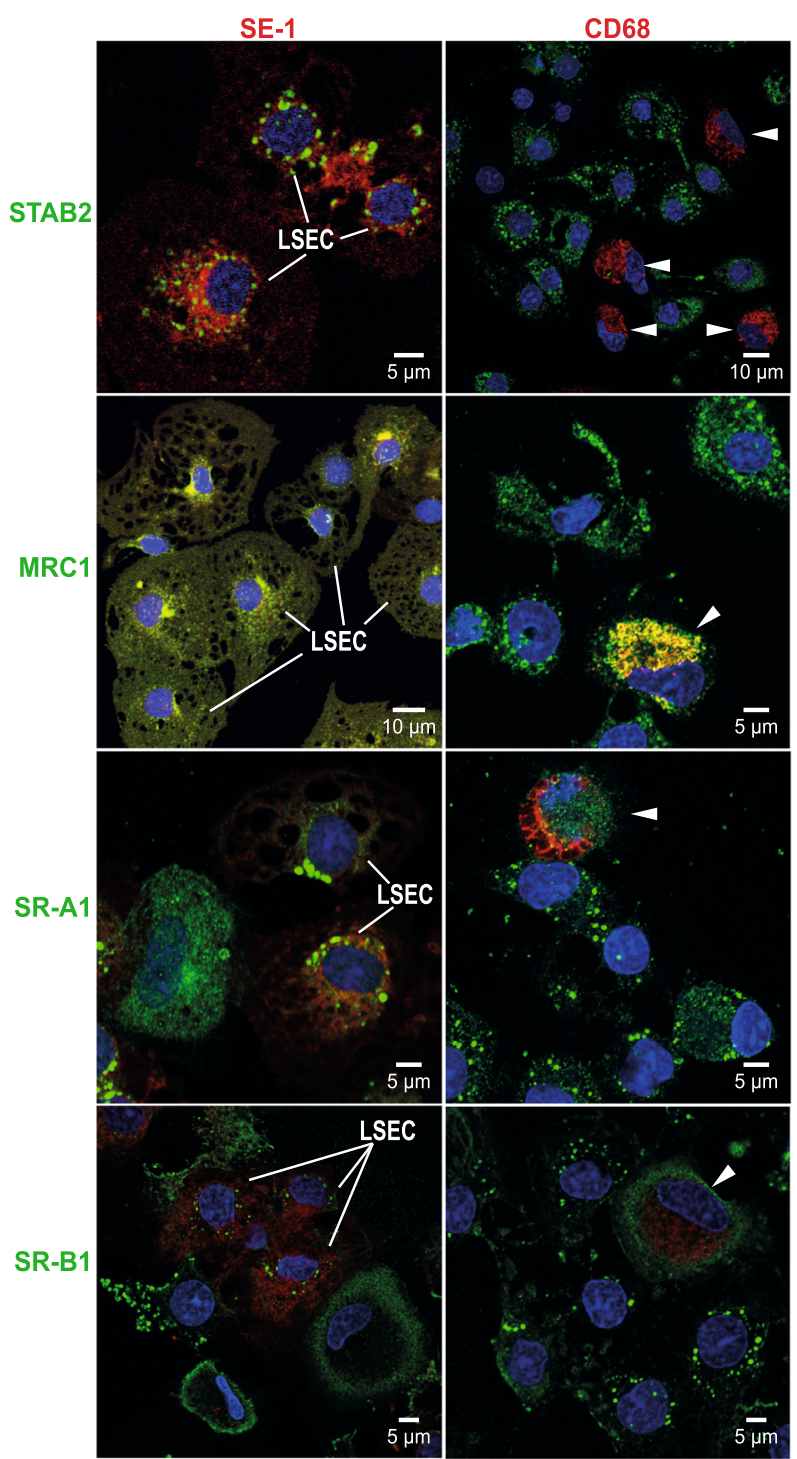

Fig. 6 (See legend on next page.) 
(See figure on previous page.)

Fig. 6 Expression of scavenger receptors and immune lectins in rat LSECs and KCs. a. Unscaled heatmaps of normalized log ${ }_{2}$ expression values $\left(\log _{2}(R P K M+1)\right.$, and $\left.\log _{2}(\mathrm{BBAQ}+1)\right)$ for scavenger receptors (SR) and C-type lectins in the KC and LSEC transcriptomes and proteomes. Underlined: Genes expressed in the transcriptome that were also present in the proteome. $\mathbf{b}$. Absolute abundance of selected SR gene products in the KC and LSEC transcriptomes and proteomes. The bar height reflects good correlation between the transcriptome and proteome data for gene products of Clec4g, Clec4m, Stab1, and Stab2 in both cell types. The abundance of gene products of Marco and Cd5I were well correlated between the KC transcriptome and proteome, while LSECs showed high abundance of these gene products only at mRNA level. c. Immune labeling of non-parenchymal liver cell (NPC) cultures for selected SRs and C-type lectins. NPCs from the 25-45\% interface on the Percoll gradient were incubated for $1 \mathrm{~h}$, then fixed $15 \mathrm{~min}$ in $4 \%$ paraformaldehyde, and double immune-labeled with antibodies to FcyRllb2 (SE-1; red fluorescence; left column), or CD68 (red fluorescence; right column), and to either stabilin-2 (STAB2; green), mannose receptor (MRC1; green), SRA1 (green), or SR-B1 (green). Overlap of green and red fluorescence is seen as yellow staining in the overlay images. Antibodies are listed in Table 1. Cell nuclei were stained with DAPI (blue). Arrow heads point to CD68 positive KCs. Antibodies to stabilin-2 and FcyRllb2 (SE-1) specifically labeled LSECS and the CD68-antibody specifically labeled KCS, whereas positive labeling for the mannose receptor, SR-A1, and SR-B1 was observed in both LSECs and KCS

immune functions in the LSECs (Additional file 9). Neither this mouse study [35], nor our present study in rat address the possibility of the existence of functionally different LSEC subpopulations. A recent single-cell transcriptomics analysis of human liver cells grouped the LSECs into two populations, of which the group enriched in LSECs from the acinar midzone and central venous zone displayed highly enriched immune pathways [68]. This supports the existence of functionally distinct LSEC subpopulations.

Reliable omics studies of isolated cell populations require access to highly pure cell preparations. Several popular markers used to identify LSECs have been associated with controversies regarding their sensitivity, specificity, selection bias, or lack proper validation [36, 37]. Here, we used SE-1-based MACS [43] to purify rat LSECs. This method utilizes the specific targeting of FcyRIIb2 [45], and has been previously reported to yield highly pure LSEC preparations [43]. The SE-1-MACS isolated cells in our experiments consisted of $>97 \%$ cells displaying the highly characteristic fenestration which is the structural hallmark of LSECs [16]. Moreover, the cell yield was relatively high (30-40 million LSECs per liver), and immune staining of liver sections using this antibody showed continuous staining along all sinusoids, similar to the LSEC specific endocytosis receptor stabilin-2, further validating SE-1/Fc $\gamma$ RIIb2 as a reliable LSEC marker in rat. The same co-distribution of SE-1 and stabilin-2 in rat liver was reported by [46]. Moreover, flow cytometry of rat NPCs showed that $97.4 \%$ of SE-1/FcyRIIb2 positive cells were also CD31 positive, supporting their endothelial identity. Rat LSEC expression of $\mathrm{CD} 31$ was confirmed by positive staining in rat liver sections, albeit more weakly than in endothelial cells in other vessels, consistent with [69]. Of note, CD31 is upregulated in LSECs in liver inflammation [36, 69, 70]. CD31 has been reported in KCs. However, a recent study employing macrophage and endothelial reporter mice concluded that what seemed to be a population of CD31 positive KCs after FACS were instead contaminating endothelial cells [71]. CD31 is regularly used as endothelial marker in studies of $\mathrm{KC}$ functions in mice [72]. In the present study CD31 staining was only observed along vessel structures in the liver tissue, and co-localized with stabilin-2 in the sinusoids.

The expression level and intralobular distribution of FcyRIIb2, and other LSEC markers may vary between species. Recently, the lack of periportal expression of Fc $\gamma$ RIIb, and LYVE-1, another commonly used LSEC marker, was reported on immune stained human liver sections [58], suggesting that isolating LSECs from human liver using these receptors as targets may introduce selection bias [36]. Notably, we found that CD36, a recommended LSEC marker in human liver [58], showed low gene and protein expression in rat LSECs, and high expression in KCs, consistent with a previous report in Sprague Dawley rat showing positive immune labeling for CD36 in KCs, but not in LSECs [59]. This shows a clear difference in the cellular distribution of CD36 in rat and human liver.

Interestingly, liver inflammation and fibrosis further affect the LSEC molecular phenotype, leading to downregulation of LYVE-1 in liver cancer and cirrhosis [73], and of FcyRIIb in non-alcoholic steatohepatitis [74]. These studies show that the optimal choice of markers of LSECs and KCs depends on animal species and the health condition of the liver.

Lack of consensus markers and heterogeneity in KCs pose challenges for rat $\mathrm{KC}$ isolation. As rat $\mathrm{KCs}$ universally express complement receptors for inactivated complement component $3 \mathrm{~b}$ [75], we used anti-rat-CD11b/c to isolate KCs by MACS with good cell yields. Staining of liver sections showed a scattered distribution with the majority of positive cells located in the periportal region where most KCs reside [76]. However, selection bias towards subpopulations of KCs cannot be excluded, as we found that CD68 positive cells showed a wider distribution within the hepatic lobule than $\mathrm{CD} 11 \mathrm{~b} / \mathrm{c}$ positive 


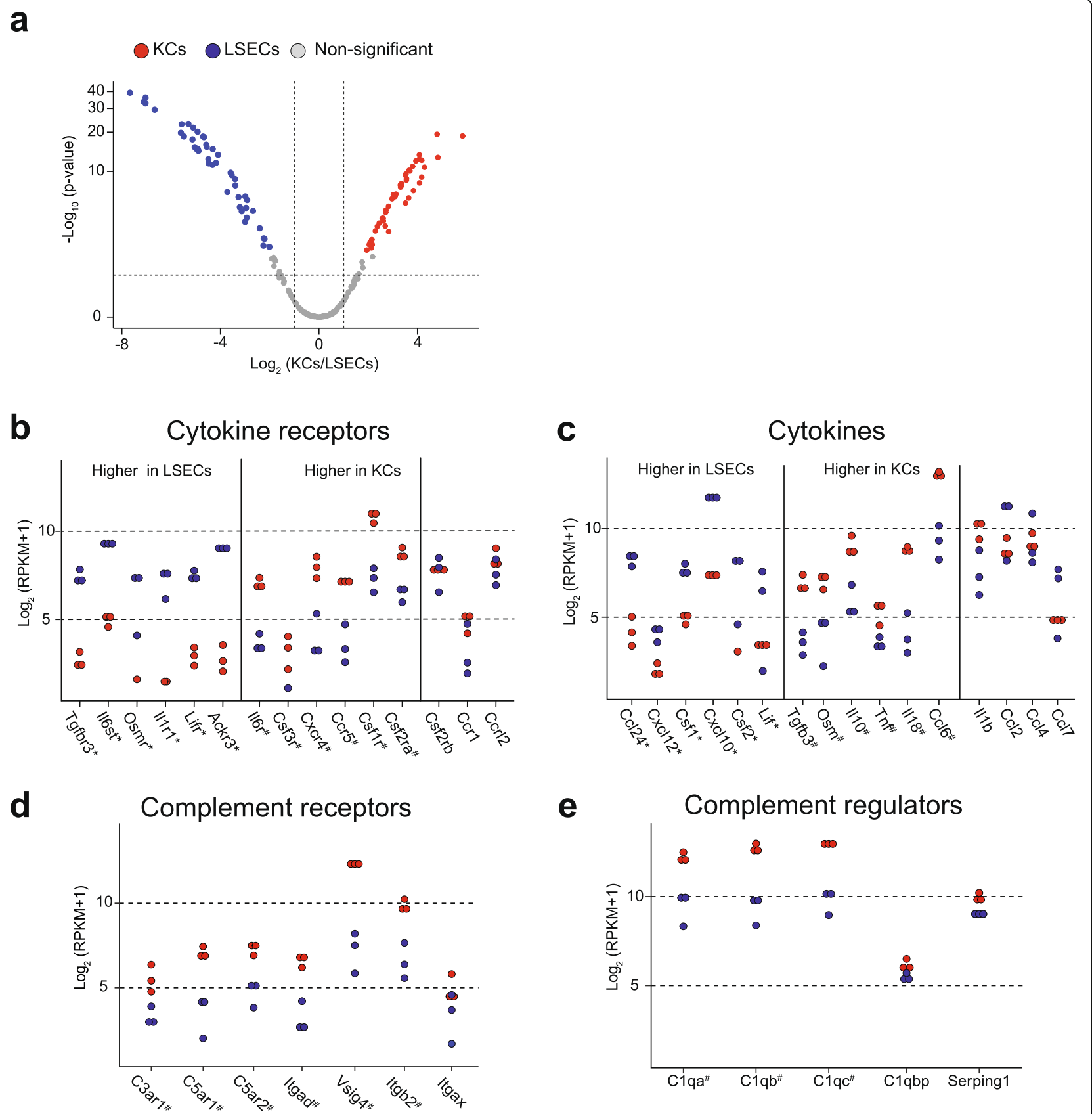

Fig. 7 Expression of immune regulatory factor genes in the rat LSEC and KC transcriptomes. The genes were associated with the terms cytokine receptor activity (GO:0004896), cytokine receptor binding (GO:0005126), complement receptor activity (GO:0004875), and complement activation (GO:0006956). a. Volcano-plot illustrating differently expressed genes. Blue dots: significantly higher expression in LSECs; red dots: significantly higher expression in KCs; gray dots: not significantly different between LSECS and KCs. Significance level: FDR $\leq 0.05$ and $\mid \log _{2}$ fold change| $\geq 1$. be. Expression of selected genes in LSECs and KCs transcriptome associated with cytokine receptor activity (b), cytokine activity (c), complement receptor activity (d), and regulators of complement activation (e). Each blue dot represents abundance, corresponding to $\log _{2}$ expression values

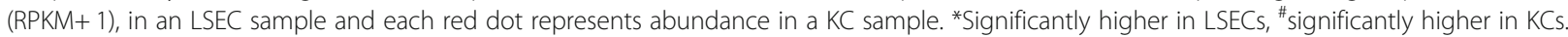
Significance level: FDR $\leq 0.05$ and $\log _{2}$ fold change| $\geq 1$

cells. Nonetheless, both markers showed the highest density of positive cells in the periportal region. Compared to the extensive literature in mice on the origin of $\mathrm{KCs}$ and differences in cell marker expression in subpopulations of liver macrophages [77], little is known about rat liver macrophage subpopulations and markers. In mouse, liver resident macrophages are reported to have the CD11b low, or CD11b negative phenotype, and 


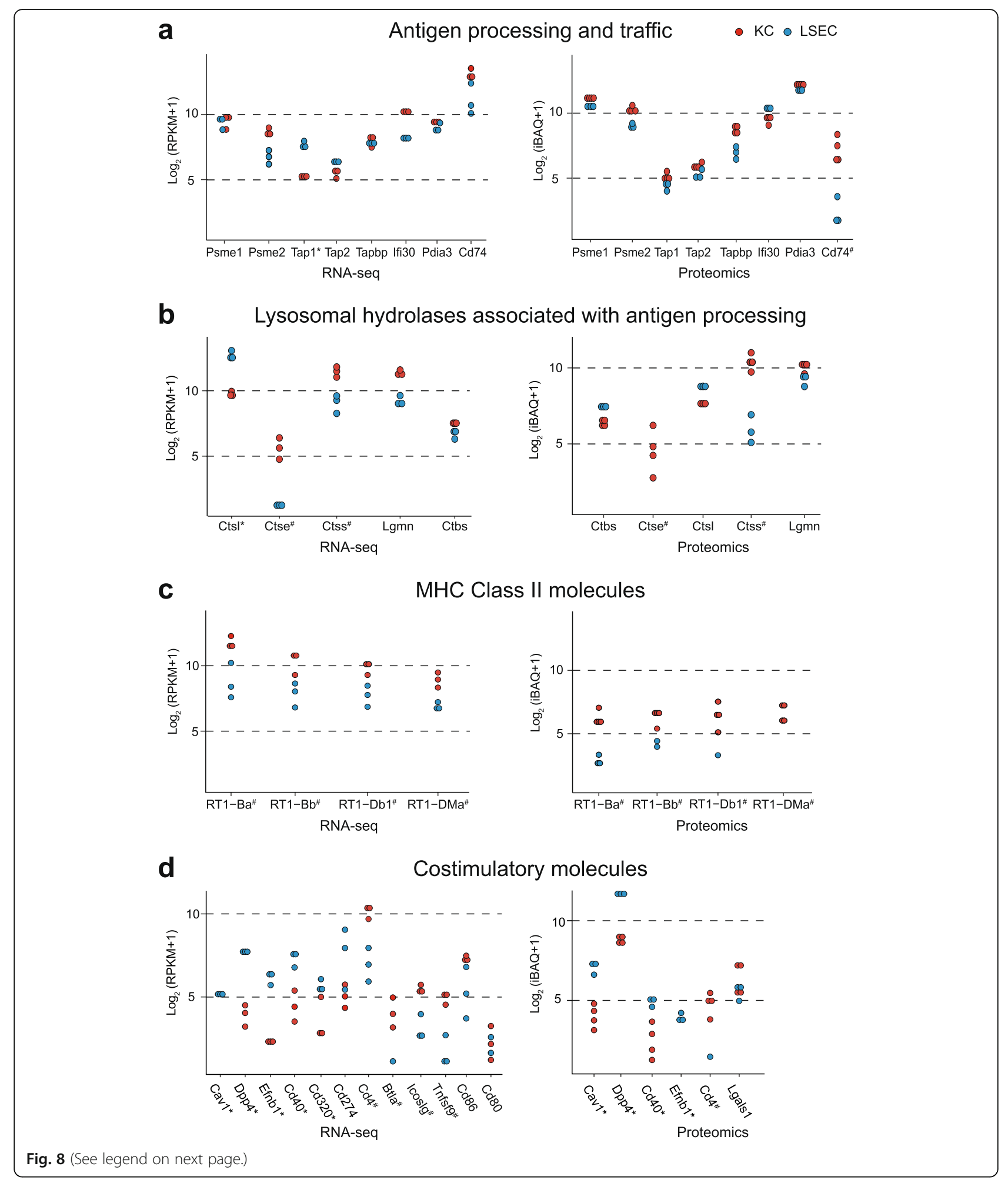


(See figure on previous page.)

Fig. 8 Expression of selected gene products associated with antigen processing and presentation (GO:0019882), and lymphocyte co-stimulation (GO:0031294) in the rat LSECs and KCs transcriptome and proteome. Each blue dot represents abundance of gene products in an LSEC sample and each red dot represents abundance in a KC sample. The dot plots on the left illustrate the abundance of mRNA ( $\left.\log _{2}(\mathrm{RPKM}+1)\right)$ in the transcriptome, and the right plots illustrate the corresponding gene expression value in the proteome $\left(\log _{2}(\mathrm{BBAQ}+1)\right)$. *Significantly higher in LSECs, ${ }^{\#}$ significantly higher in KCs. Significance level: FDR $\leq 0.05$ and $\mid \log _{2}$ fold change| $\geq 1$. a. Gene products involved in antigen processing (immune proteases: Psme1, Psme2), transport of processed peptide into the endosome for loading into MHC molecules (Tap1, Tap2, Tapbp), accessory proteins in loading and sorting of MHC molecules to endolysosome (Ifi30, Pdia3), and the invariant chain (Cd74). b. Lysosomal hydrolases annotated to be associated with MHC class II antigen processing. c. MHC class II gene products. d. Co-stimulatory factors involved in lymphocyte activation

the CD11hi phenotype includes bone marrow macrophages that have migrated to the liver [78]. The CD11b/c MACS-purified liver macrophages in our study expressed high levels of CRIg (VSig4), CD68 and CD163, which are validated markers of resident $\mathrm{KCs}$ [79-81], indicating that they are KCs, but our study cannot confirm whether some have been recruited from bone marrow. However, the cells were isolated from young, healthy rats with normal livers, and the livers were perfused free of blood with perfusion buffer before starting the recirculation system with collagenase buffer in order to disperse the cells, which minimizes the risk of isolating blood monocytes. The source of macrophages in liver has been reported to affect expression levels of enzymes and receptors [82]. Interestingly, two recent studies in mice showed that bone marrowderived resident liver macrophages, and KCs of yolk sac origin have highly similar gene expression profiles, that is different from that of monocytes [72, 83].

CD45 is used as a negative selection criterion for isolation of human and mouse LSECs [36], whereas the same marker has been reported to be expressed in rat LSECs

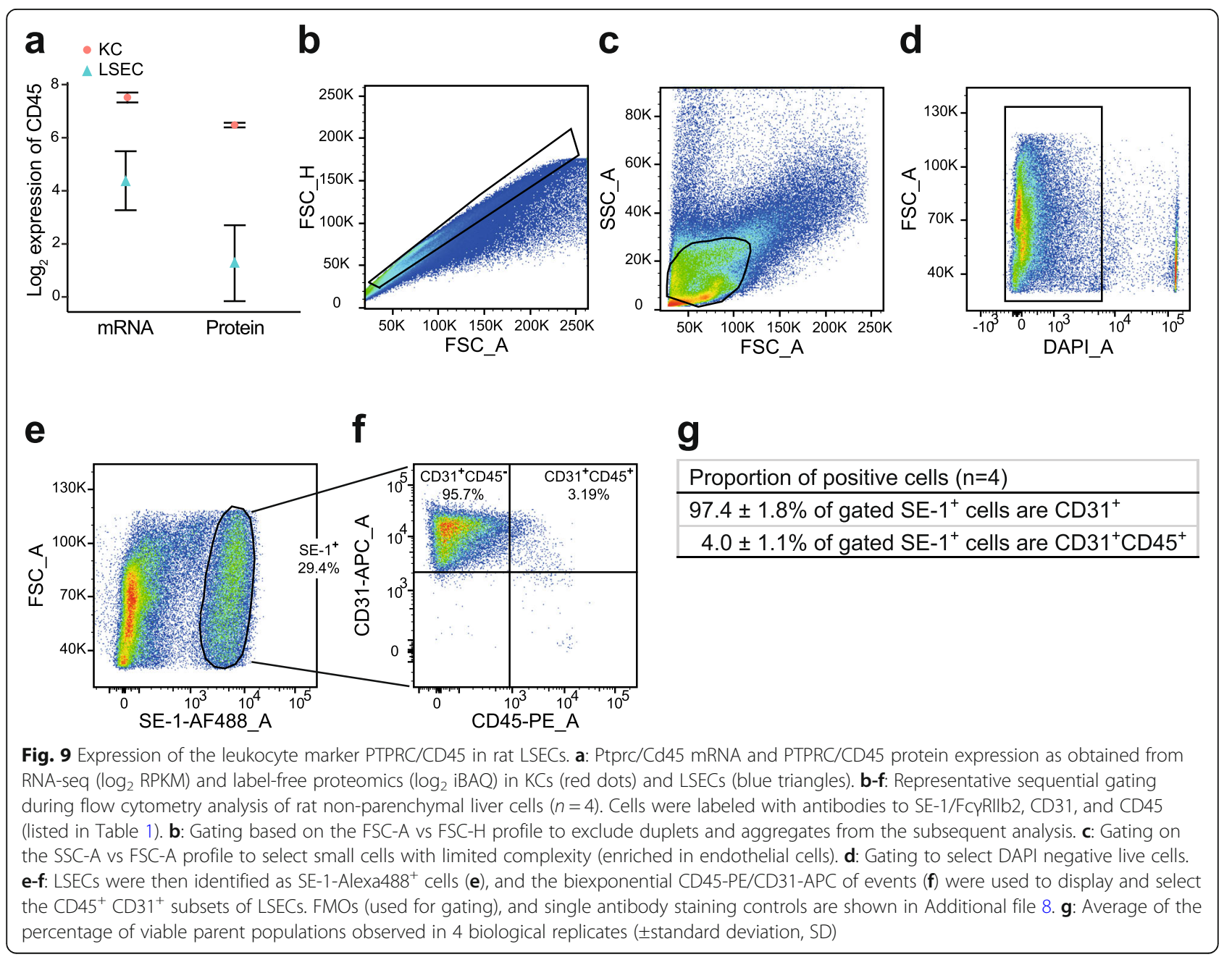


$[38,84]$. In our study we observed a low expression of this marker in the LSEC transcriptomes and proteome compared to KCs, and flow cytometry showed that $4 \%$ of SE-1 positive small NPCs with limited complexity were $\mathrm{CD} 31^{+} \mathrm{CD} 45^{+}$cells, which indicates CD45 expression in a small subpopulation of rat LSECs. Expression of CD45 in rat LSECs has been linked to recruitment of LSECs from bone marrow $[66,84]$.

Several SRs and C-type lectins were expressed at high density in the rat LSECs and KCs. This enables the two cells to recognize a wide variety of foreign and endogenous, modified substances, thus maintaining homeostasis [5]. In LSECs, the very high expression of stabilin-1, stabilin-2, FcyRIIb2, and the macrophage mannose receptor suggests that these are the crucial receptors contributing to the remarkably high endocytic capacity of LSECs [5, 16, 18]. In contrast to stabilin-1/-2 and the FcyRIIb2 which are LSEC specific in liver, the mannose receptor is also abundant in KCs. This receptor has traditionally been associated with M2 polarized macrophages but is present in LSECs of all mammalian species examined (rat, mouse, pig, human), while its expression in KCs varies between studies [5]. Interestingly, the macrophage mannose receptor has been reported to be absent in human KCs [85]. Functional studies in rat show that after intravenous injection of soluble ligands for this receptor, such as lysosomal enzymes [86-88], C-terminal procollagen propeptides [13], or ovalbumin [89], much of the ligand is rapidly cleared from blood by uptake in LSECs, which show a higher uptake per cell than in KCs. This points to LSECs as more efficient pinocytic cells.

We also observed mRNA expression in LSEC of some SRs not previously reported in these cells at steady state including members of SR-class A (Marco), SR-class D (Cd68, Ackr3), SR-class G (Lgals3bp, Cxcl16) and SR-class I (Cd51, Cd163 and Dmbt1). However, these SRs were either not detected or showed low expression in the LSEC proteome. This may be due to post-transcriptional, translational, and/or protein degradation regulation, and/or the effect of the isolation procedure which may affect the expression. A previous microarray study [39] indicated changes in rat LSEC gene expression already after $2 \mathrm{~h}$ in culture. Importantly, proteomics is biased towards identification of highly abundant proteins. Despite high LSEC and $\mathrm{KC}$ purity in our experiments we cannot exclude that a low level in the other cell type might result from minute numbers of contaminating cells for some of the genes. Nonetheless, the expression pattern of these SRs was similar to that of LRP1, which has been functionally validated in LSECs [90], and CD45, which we showed by flow cytometry to be expressed in $4 \%$ of the LSECs. This suggests that a minor subset of LSECs may express these markers. However, this needs to be further explored in single cell experiments in rat liver cells.
Immune regulatory factors are important in maintaining liver homeostasis, and their dysregulation causes sustained inflammation. In the present study of cells at steady state we found that LSECs predominantly expressed Csf1, Ccl24 and Cxcl12, which affect recruiting, maintenance and homeostasis of other immune cells [63, 91, 92]. Our observation that LSECs express the chemokine scavenger receptor Ackr3 suggests a role for these cells in creating chemokine gradients and thus regulating the overall immune milieu of the sinusoids. $\mathrm{KCs}$ on the other hand, more abundantly expressed cytokines such as Illb and TNF- $\alpha$ known to affect LSEC endocytic functions [93]. In accordance with a proteomics study in mice [42], rat KCs were also more tuned to positive regulation of complement activation by higher expression of triggers of complement activation. Interestingly, rat LSECs and KCs respond to inflammatory mediators in a generally similar manner, developing into pro- and anti-inflammatory subpopulations, indicating that both cells contribute to innate immune responses in liver [94].

Furthermore, we found that rat LSECs express gene products associated with processing and presentation of antigen required for activation of naïve $\left(\mathrm{CD}^{+}\right.$and $\left.\mathrm{CD} 8^{+}\right)$ $\mathrm{T}$ cells. Most of these genes were significantly lower expressed in LSECs than in KCs and their function in rat LSECs will need further validation. This finding nevertheless supports functional studies in mouse models concluding that LSECs are antigen presenting cells [1, 32, 95-98]. In physiological conditions, LSECs contribute to generation of $\mathrm{T}$ regulatory cells and induction of immune tolerance. However, after fibrotic liver injury due to hepatotoxins, mouse LSECs become proinflammatory, and induce an immunogenic T cell phenotype [99].

\section{Conclusions}

Good resolution was achieved between rat LSECs and $\mathrm{KCs}$, enabling reliable and comprehensive molecular characterization of the cells at steady state. The study showed complementarity of scavenging and immune functions in LSECs and KCs. Both cells expressed high levels of SRs and immune lectins, of which some were present in both cells. Of note, inter-species expression differences for some receptors, as evident from the literature, highlight the need for thorough studies on gene expression in different animal models. We propose that the many common phenotypic and functional traits shared between LSECs and KCs is a consequence of the specialized sinusoidal environment along with the functional demand of the sinusoid, causing the cells to develop complementary and overlapping functions. Our study underlines the importance of taking both cells into consideration in studies of liver immunity. Furthermore, LSECs and KCs play a major role in the, often unwanted, 
liver uptake of large molecule biopharmaceuticals and nano-formulations [23] preventing drugs from reaching their intended targets. Of note, major off-target drug accumulation in these cells may cause LSEC toxicity, which subsequently may result in liver toxicity. Our results contribute to understanding these uptake mechanisms to a greater detail, which is a prerequisite to develop remedies to reduce unwanted liver uptake.

\section{Methods}

\section{Animals and ethics statement}

Sprague Dawley, Crl:CD (SD), male rats, aged 6-11 weeks were used in the experiments. The animals were obtained directly from Charles River Laboratories (Sulzfeld, Germany). The rats were group housed (3 rats per cage) in 1354G Eurostandard type III conventional cages (Tecniplast, Italy) with aspen bedding (Scanbur, Norway), and with nesting material, houses, and aspen bricks (all from Datasand Ltd., Manchester, UK) as environmental enrichment. The rats were housed under controlled conditions $\left(21^{\circ} \mathrm{C} \pm 1{ }^{\circ} \mathrm{C}\right.$, relative humidity $55 \% \pm 10 \%$, and $12 \mathrm{~h} \mathrm{light} / 12 \mathrm{~h}$ dark cycle) at the specific pathogen free animal research facility at the University of Tromsø (UiT) - The Arctic University of Norway. The rats had free access to water and standard chow (RM1-E, Special Diet Service, UK), and were acclimatized for at least one week before experiments. Prior to the experiment and during acclimation period, animal health was assessed daily by experienced animal technicians. The experimental protocols and animal handling were approved by the competent institutional authority and the National Animal Research Authority at the Norwegian Food Safety Authority (Mattilsynet; Approval IDs: 4001, 8455, and 0817), and experiments were performed in compliance with the European Convention for the protection of Vertebrate Animals used for Experimental and Other Scientific Purposes. A total of 25 rats were used in this study. All animals were euthanized. While in deep surgical anesthesia (for anesthesia protocol see Method section "Rat liver perfusion, LSEC and $\mathrm{KC}$ isolation, and cell purity evaluation"), the vena cava was cut causing exsanguination. For liver tissue sampling for immune histochemistry, the animal was euthanized by $\mathrm{CO}_{2}$ according to the requirement in Directive 2010/63/EU in a pre-set system ensuring gradual fill and appropriate exposure time ("Automatic $\mathrm{CO}_{2}$ Delivery System", Vet Tech Ltd., UK), and organs were sampled from the dead animal.

\section{Rat liver perfusion, LSEC and KC isolation, and cell purity evaluation}

Non-parenchymal liver cells (NPCs) were isolated essentially as described in [100], with some modifications. The surgical procedure was performed in the morning (between $8 \mathrm{a} . \mathrm{m}$. and $10 \mathrm{a} . \mathrm{m}$.) in the animal research facility at UiT - The Arctic University of Norway. The rats (body weight 200-320 g) were anesthetized with either 1) a combination of ketamine hydrochloride (Ketalar 50 $\mathrm{mg} / \mathrm{mL}$; Pfizer, Norway) and medetomidine hydrochloride (Domitor vet $1 \mathrm{mg} / \mathrm{mL}$, Orion Corporation, Finland); dose of mixture: $0.15 \mathrm{~mL}$ Ketalar $/ 100 \mathrm{~g} \mathrm{BW}$ and $0.05 \mathrm{~mL}$ Domitor /100 g BW, administered subcutaneously; or 2) with a mixture (ZRF-mix) of zolazepam /tiletamine hydrochloride 12.9/12.9 mg/mL (Zoletil forte vet, Virbac, Norway), xylazine $1.8 \mathrm{mg} / \mathrm{mL}$ (Rompun, Bayer Nordic, Norway) and fentanyl $10.3 \mu \mathrm{g} / \mathrm{mL}$ (Actavis, Norway); dose of mixture: $2 \mathrm{~mL} / \mathrm{kg} \mathrm{BW}$, administered intraperitoneally. Anesthetic depth was assessed prior to and during the operation procedure to ensure deep surgical anesthesia. The abdomen was opened in the midline, and the intestines gently pushed to the side in order to expose the liver and portal vein. A catheter connected to a peristaltic pump driven perfusion system was inserted into the portal vein and fixed to the vein by a suture, and the caudal vena cava was cut to allow outflow of buffer from the liver and exsanguination of the animal. The liver was then separated from the surrounding tissues by cutting all ligaments and placed on a mesh on the top of a cylinder, where run-through buffer was collected. The liver lobes were perfused free of blood with $250 \mathrm{ml}$ of a calcium-free HEPES-based buffer [100], then perfused for $10 \mathrm{~min}$ (flow rate $30 \mathrm{ml} / \mathrm{min}$ ) in a recirculation system, with $50 \mathrm{ml}$ of a calcium-containing HEPESbased buffer [100] with $0.6 \mathrm{mg} / \mathrm{ml}$ collagenase (Worthington, Lot: X4B7108, Worthington Biochemical Corp., Lakewood, NJ). Hepatocytes were sedimented by low speed differential centrifugation ( $50 \mathrm{~g}, 2 \mathrm{minx} 3$ ) leaving mainly NPCs in the supernatant which was decanted and centrifuged ( $300 \mathrm{~g}, 10 \mathrm{~min}$ ). The resulting pellet was resuspended, loaded onto a two-step Percoll gradient (GE Healthcare, Uppsala, Sweden), and centrifuged at $1350 \mathrm{~g}$ for $30 \mathrm{~min}$. Cells at the $25-45 \%$ Percoll interface, enriched in KCs and LSECs, were collected. To purify LSECs, NPCs were incubated with the M-rSE-1 antibody targeting FcyRIIb2 (CD32b) [45] (Table 1) for $30 \mathrm{~min}$ at $4{ }^{\circ} \mathrm{C}$ in autoMACS rinsing solution with $1 \%$ BSA (Miltenyi Biotec Norden AB, Lund, Sweden), washed, and incubated with anti-mouse IgG2a $+b$ MicroBeads for 30 $\min$ at $4{ }^{\circ} \mathrm{C}$. To purify KCs, NPCs were incubated with a biotinylated-CD11b/c antibody (Table 1) followed by incubation with Streptavidin MicroBeads. Labeled NPCs were eluted through an LS-column in a MidiMACS Separator (Miltenyi) according to the manufacturer's protocol. Typical cell yields were 30-40 million LSECs, and 10 million KCs per rat liver. LSECs and KCs were harvested from separate animals to maximize cell yields.

LSECs $\left(0.25\right.$ million cells $\left./ \mathrm{cm}^{2}\right)$ were seeded in $100 \mathrm{~mm}$ tissue culture dishes (RNA-seq: Nunclon, ThermoFisher 
Scientific, Waltham, MA; Proteomics: Sarstedt, Nümbrecht, Germany) coated with $2.9 \mu \mathrm{g} / \mathrm{ml}$ bovine collagen type I (Advanced BioMatrix, San Diego, CA, Cat.\#5005), in RPMI-1640 cell culture medium supplemented with 20 $\mathrm{mM}$ sodium bicarbonate, $0.0006 \%$ penicillin, and $0.01 \%$ streptomycin (Sigma-Aldrich, St. Louis, MO, Cat.\#R8758), and allowed to attach for $1 \mathrm{~h}$. KCs $\left(0.17\right.$ million cells $\left./ \mathrm{cm}^{2}\right)$ were seeded on uncoated $100 \mathrm{~mm}$ dishes, and incubated for $30 \mathrm{~min}$. The cells were then gently washed with prewarmed $\left(37^{\circ} \mathrm{C}\right)$ medium before extraction of RNA for high throughput RNA-sequencing, or protein for nonlabel quantitative proteomics.

The purity and morphology of MACS-isolated cells were assessed by phase contrast microscopy (all cultures), scanning electron microscopy (SEM; LSECs for transcriptomic and proteomic analyses, and KCs for proteomic analyses), and immune cytochemistry (LSECs and $\mathrm{KCs}$ for proteomic analyses) using antibodies against glial fibrillary acidic protein (GFAP; stellate cell marker), stabilin-2 (LSEC marker) [24, 25], CD11b/c, and SE-1/ FcyRIIb2 (Table 1). The cells for purity assessment by SEM and immune cytochemistry were from the same preparations and cultured in parallel to the cells used for omics experiments, and were seeded in similar density, incubated and washed as for the omics experiments.

\section{LSEC and KC mRNA transcriptome sequencing}

Total RNA was extracted with the RNeasy Mini Kit (Qiagen, Hilden, Germany, Cat.\#74,104). PolyA-enriched RNA from LSECs was then purified by MicroPoly(A)Purist $^{\text {th }}$ Kit (Life Technologies, ThermoFisher Scientific), whereas Dynabeads ${ }^{\circ}$ mRNA DIRECT ${ }^{\mathrm{m}}$ Micro Kit (Ambion, ThermoFisher, Cat.\#61,021) was used to purify mRNA from KCs. Quality and quantity of mRNA were measured with Agilent RNA 6000 Pico Kit (Agilent Technologies, Santa Clara, CA, Cat.\#5067-1513). The mRNAs were fragmented and reverse transcribed by Ion Total RNA-Seq Kit v2 (Life Technologies) according the manufacturer's instructions. Three LSEC transcriptome libraries representing 3 biological replicates, each from one individual rat, and three $\mathrm{KC}$ transcriptome libraries (3 biological replicates; each from the pooled KC mRNA from 2 rats) were constructed. Templates were prepared by Ion OneTouch ${ }^{\text {tx }} 200$ Template Kit v2 DL and Ion PGM $^{\text {ms }}$ Sequencing 300 Kit, loaded on Ion 316 chips, and sequenced with the Ion Torrent Personal Genome Machine (Life Technologies). We generated 1.09 billion nucleotide sequence data from the LSEC pool, corresponding to approximately 8.2 million mapped reads, and 0.93 billion nucleotide sequence data from the KS pool, corresponding to 6.5 million mapped reads. Additional file 10 lists the information on number of raw reads, reads after trimming, average length of the trimmed sequences and the number of reads mapped to the reference genome for each biological replicate.

\section{Transcriptomic data analyses}

Bioinformatics analyses were performed with the CLC Genomics Workbench 8.0.2 (Qiagen ${ }^{\circledR}$ Bioinformatics), and the Bioconductor project. Raw sequencing reads were subjected to adaptor trimming, followed by quality trimming (Ambiguous limit $=2$ and Quality limit $=0.05$ ). Based on quality reports the reads were filtered based on length (minimum 15 and maximum 300 nucleotides); then 10 nucleotides from the $5^{\prime}$ end, and 20 nucleotides from the 3' end were removed. All samples from the 6 experiments (LSECs, $n=3$; KCs, $\mathrm{n}=3$ ) were included in the analysis as they were deemed homogenous with respect to 5-mer analysis and GC contents, and were free of ambiguous bases. RNA-seq analysis was performed with CLC Genomics Grid Worker 7.0.1. The reads were mapped to Rattus norvegicus reference genome (Rnor 6.0 [101], which generated the gene expression counts and RPKM (reads per kilobase of exon model per million mapped reads [56]) values. Other parameter values used in mapping were: mismatch cost $=2$, insertion $\operatorname{cost}=3$, deletion cost $=3$, length and similarity fraction $=$ 0.8 each, allowed maximum number of hits for a read $=$ 10 , and map to inter-genic regions. We used the edgeR (3.28.0)-limma (3.42.0) workflow as described in [102] to analyze the gene-level count data, using the following criteria: genes with low expression were filtered out using the filterByExpr function, and the remaining genes were considered to be expressed and were used in subsequent data analyses. Heteroscedasticity of the data was removed with voomWithQualityWeights function available in the limma package [103], after trimmed mean of M-values (TMM) normalization.

\section{Preparation of samples for quantitative proteomics, and tandem mass spectrometry (LC-MS/MS)}

MACS-isolated cells were allowed to adhere for $30 \mathrm{~min}$ (KC, $n=4$ biological replicates, each from one individual rat) or $1 \mathrm{~h}$ (LSECs, $\mathrm{n}=3$ biological replicates, each from one individual rat) to $100 \mathrm{~mm}$ petri dishes as described under "Rat liver perfusion, LSEC and KC isolation, and cell purity evaluation". The cells were washed with RPMI-1640 $\left(37^{\circ} \mathrm{C}\right)$ to remove non-adherent cells, then immediately scraped out in triethylammonium bicarbonate (TEAB) solution (ThermoFisher) to collect protein lysate, which was centrifuged to remove cellular debris. Protein pellets were resuspended in $2 \mathrm{M}$ urea and 50 $\mathrm{mM}$ TEAB. Samples of $20 \mu \mathrm{g}$ protein were digested for $6 \mathrm{~h}$ in 1:100 (w/w) Lysyl Endopeptidase ${ }^{\circ}$ (Fujifilm Wako Chemicals Europe GmBH, Neuss, Germany), then diluted to $1 \mathrm{M}$ urea and digested overnight with $1 / 20$ (w/ w) trypsin (V511A, Promega Corporation, Madison, 
WI). OMIX C18 tips (Varian Inc., Palo Alto, CA) were used for sample cleanup and concentration. Peptide mixtures containing $0.1 \%$ formic acid were loaded onto the Thermo Fisher Scientific EASY-nLC1000 system and EASY-Spray column $(\mathrm{C} 18,2 \mu \mathrm{m}, 100 \AA$, $50 \mu \mathrm{m}, 50 \mathrm{~cm})$. Peptides were fractionated using a $2-100 \%$ acetonitrile gradient in $0.1 \%$ formic acid over $50 \mathrm{~min}$ at a flow rate of $250 \mathrm{nl} / \mathrm{min}$. Separated peptides were analyzed using Thermo Scientific Q-Exactive mass spectrometer. Data was collected in data dependent mode using a Top10 method.

\section{Label-free proteomics analyses}

Raw files from the Q-Exactive MS/MS were analysed using the quantitative proteomics software MaxQuant [104] (version 1.5.6.0). Proteins were identified using the built in Andromeda search engine using the UniProtKB Rattus norvegicus database (Jan 2017). Main search peptide tolerance was set to $4.5 \mathrm{ppm}$ and MS/MS mass tolerance was set to $20 \mathrm{ppm}$. An FDR ratio of 0.01 was needed to give a protein identification. At least 2 peptides had to be quantified to give a quantitation value.

To estimate protein abundance, $\mathrm{iBAQ}$ values (i.e. the sum of peak intensities of all tryptic peptides matching to a specific protein divided by the number of theoretically observable peptides [105]) were generated with MaxQuant, and used for downstream quantitative proteomic analysis with Perseus (version 1.6.02). Perseus, R statistical computing (version 3.4.1), and Bioconductor (version 3.5) environments were used for bioinformatics and statistical analyses. The generated list of proteins was filtered to remove protein hits that were annotated as only identified by site, contaminants and reverse hits in Perseus. All samples for proteomics were run twice on LC-MS/MS and the median of the iBAQ values of the two runs was considered as the expressed iBAQ value. The annotation of the protein IDs and the corresponding genes were carefully curated. The iBAQ values of all protein IDs corresponding to a specific gene were added to remove redundancy in gene annotation. The resulting $\mathrm{iBAQ}$ values were then scaled to make an equal column sum. Protein with low expression were filtered using the filterByExpr function in edgeR-limma. The filtered data were rescaled to per million using the $\mathrm{cpm}$ function, followed by TMM normalization. The term "iBAQ" in figures and text refers to these normalized values and were used in the subsequent analyses. The same edge-R-limma workflow as used in the RNA-seq data analysis was used for the subsequent differential analysis of the proteomics data.

\section{Data integration and visualization}

In order to compare RNA-seq data with proteomics data the expression of gene products in the RNA-seq dataset that corresponded to protein IDs in the proteomics data were reevaluated by summing up the counts of all relevant genes. $\log _{2}$ transformed expression values with prior addition of an offset of 1 were used in the visualization, unless mentioned otherwise.

\section{Immune labeling of cells and liver tissue}

MACS isolated LSECs and KCs (parallel cultures to proteomics experiments) were seeded on collagen coated glass coverslips (LSECs) or uncoated glass coverslips (KCs) at similar density as with the omics experiments, and incubated and washed in the same way, before fixation $15 \mathrm{~min}$ in $4 \%$ paraformaldehyde (PFA) in PBS, $\mathrm{pH}$ 7.2. NPCs from the $25-45 \%$ interface of the Percoll gradient were seeded on collagen-coated glass coverslips, incubated for $1 \mathrm{~h}$, washed and fixed $15 \mathrm{~min}$ in $4 \%$ PFA. Liver samples were embedded in TissueTek OCT compound (Sakura Finetek, Zoeterwoude, Netherlands), snap frozen in liquid nitrogen, and stored at $-70{ }^{\circ} \mathrm{C}$. Cryosections, $8-10 \mu \mathrm{m}$, were fixed in cold acetone for $10 \mathrm{~min}$, then incubated in blocking buffer for $1 \mathrm{~h}$, and immune labeled. All antibodies (Table 1) were diluted in blocking buffer, which was $1 \%$ BSA and $2 \%$ goat serum in PHEM buffer (w/v: 1.81\% PIPES, 0.65\% HEPES, 0.38\% EGTA, $\left.0.1 \% \mathrm{MgSO}_{4}\right), \mathrm{pH} 7$, when labeling cryosections, and $1 \%$ BSA in tris buffered saline, 0.05\% Tween 20, pH 8.4, when labeling cells. Sections and cells were incubated with primary antibody at $4{ }^{\circ} \mathrm{C}$ overnight, then washed and labeled with secondary antibody for $1 \mathrm{~h}$ at room temperature. Isotype controls or non-immune $\operatorname{IgG}$ controls were used in all immune staining experiments. $\mathrm{Nu}$ clei were stained with DAPI (1:1000 in PBS; SigmaAldrich). Confocal microscopy was performed using a Zeiss LSM780 system (Carl Zeiss, Oberkochen, Germany). For purity assessment by differential counting of immune labeled MACS isolated cells, images were taken from 5 different areas of the cultures, including at least 350 cells from each CD11b/c-MACS isolation, and 700 cells from each SE-1-MACS isolation in the differential cell count.

\section{Scanning Electron Microscopy (SEM)}

SE-1-MACS-isolated LSECs (parallel cultures to proteomics experiments) were seeded on collagen coated 24well tissue culture plates for $1 \mathrm{~h}$, whereas CD11b/c MACS-isolated KCs were seeded for $30 \mathrm{~min}$ on uncoated 24-well plates. Cells were gently washed with medium before fixation in McDowell's fixative (4\% PFA, $1 \%$ glutaraldehyde, in phosphate buffer, pH 7.2). Fixed cultures were stamped out from the plate and cells processed for SEM using the following protocol: 1) 3x wash in PHEM buffer, $\mathrm{pH} 7$; 2) $1 \mathrm{~h}$ incubation with $1 \%$ tannic acid in PHEM; 3) 3x wash in PHEM; 4) $30 \mathrm{~min}$ in $1 \%$ osmium tetroxide in $\mathrm{H}_{2} \mathrm{O}$; 5) 3x wash in PHEM; 6) dehydration 
in graded ethanol (30-100\%); 7) drying in hexamethyldisilazane (Sigma-Aldrich). Specimens coated with $10 \mathrm{~nm}$ gold/palladium were scanned and imaged in a Zeiss Sigma Field Emission Scanning electron microscope (Carl Zeiss) at $2 \mathrm{kV}$. For cell purity assessment, high resolution overview images were taken at random from at least 5 different areas per cell culture (LSEC and KC samples for proteomics experiments), or at least 3 areas per culture (LSEC samples for RNA-seq experiments). Cells from all areas were included in the differential cell count, including at least 600 cells per KC sample, and 800 cells per LSEC sample in the cell purity assessment for proteomics, and $280-470$ cells per LSEC sample in the cell purity assessment for RNA-seq.

\section{Flow cytometry}

Samples of $0.5-1 \times 10^{6}$ NPCs collected from the $25-45 \%$ interface of the Percoll gradient were stained with antibodies to CD45, CD31, and SE-1/FcyRIIb2 (Table 1) at $4{ }^{\circ} \mathrm{C}$ in dark for $20 \mathrm{~min}$. Data acquisition and analysis were performed in a BD LSRFortessa ${ }^{\text {Tx }}$ Cell Analyzer (BD Biosciences, San Jose, CA) with BD FACSDiva Software version 8.0.1. The laser configuration and the PTM voltage were calibrated prior running the samples. The PTM voltage was adjusted during the experiments using the single stained controls. The data were further quality checked and analyzed with FlowJo V10.7.1 software (BD Biosciences). The AutoSpill/AutoSpread spillover algorithm available in Flowjo 10.7.1 was used to address the compensation issue using single stained controls post acquisitions. Isotype controls, single antibody controls, and FMO controls were used to properly interpret the acquired data. DAPI staining was performed to discriminate between live and dead NPCs. An excess of 100,000 events were recorded and analyzed in every test within each biological replicate $(n=4)$, each representing one individual rat.

\section{Statistical tests}

The descriptive and inferential statistical analyses and graphical plots of the transcriptomics and proteomics data were performed either in the R/Bioconductor or the Perseus environment. RNA-seq analysis was performed with CLC Genomics Grid Worker 7.0.1. The genes/proteins retained after filtering of low expressed gene/protein using filterByExpr function were deemed to be expressed and were used in subsequent data analyses. Heteroscedasticity of the data was removed with voomWithQualityWeights function available in the limma package [103], after trimmed mean of M-values (TMM) normalization. Differential expression analysis of the transcriptomics and the proteomics data was tested with edgeR (3.28.0)-limma (3.42.0) workflow as described in [102], with FDR multiple correction [103], as described under "Transcriptomic data analyses" and "Label-free proteomics analyses". The genes/proteins were identified as differentially expressed when the $\mid \log _{2}$ fold change $\mid$ $\geq 1$ and $F D R \leq 0.05$. All samples were included in the omics analyses. LSECs and KCs were compared at functional level using gene set enrichment analysis (GSEA) $[49,50]$ on gene lists ranked based on expression level with priori defined collection of annotated gene sets from Molecular Signatures Database. The gene sets were considered significantly enriched if FDR q-value $\leq 0.05$.

\section{Supplementary Information}

The online version contains supplementary material available at https://doi. org/10.1186/s12860-020-00331-9.

Additional file 1. Gene set enrichment analysis. The Excel file (.x/s) shows the output of gene set enrichment analysis (GSEA) $[49,50]$ of preranked gene lists from the rat LSEC and KC RNA-seq datasets, associated with Gene Ontology (GO) biological processes (BP). The genes were preranked based on expression. We have used the $\mathrm{C} 5$ collection of annotated gene sets in the Molecular Signatures Database (release 6.2; BP) [53] which consists of gene sets derived from $\mathrm{GO}[51,52]$. Name of worksheets: "GSEA_plot", "GSEA_RNAseq_LSEC_BP", and "GSEA_RNAseq_KC_BP". The worksheet named "GSEA_Plot" contains the selected enriched BPs shown in Fig. 4.

Additional file 2. List of all expressed genes in the RNA-seq and proteomics datasets. Excel file (.xIs) with all genes and proteins that were deemed expressed, as defined in Methods, and used in the downstream analysis and visualization of data. The worksheet named "RNA_seq_whole expressed" contains the data from the RNA-seq experiments (expression values in RPKM), and differential expression analysis results. The worksheet named "Proteomics_whole expressed" contains the data from the labelfree proteomic experiments (expression values in iBAQ), and differential expression analysis results.

Additional file 3. Genes and proteins associated with immune system processes. Excel file (.xls) with the list of genes and proteins associated with the term immune system processes (GO:0002376) presented in the two heatmaps in Fig. 5a, along with their associated expression values (RPKM, or iBAQ). The two worksheets are named "Immune genes_RPKM_RNAseq", and "Immune genes_iBAQ_proteomics". Of note, for visualization, $\log _{2}(\mathrm{RPKM}+1)$ and $\log _{2}(\mathrm{iBAQ}+1)$ were used in the heatmaps in Fig. 5a.

Additional file 4. Scavenger receptors and C-type lectins. Excel file (.xIs) with the list of genes and proteins presented in the two heatmaps in Fig. $6 \mathrm{a}$, along with their associated expression values (RPKM, or iBAQ). The two worksheets are named "SRs\&lections_RPKM_RNAseq) and "SRs\&lectins_iBAQ_proteomics". For visualization, $\log _{2}(\mathrm{RPKM}+1)$ and $\log _{2}(\mathrm{iBAQ}+1)$ were used in Fig. 6.

Additional file 5. Immune histochemistry for CD68. Immune histochemistry of acetone-fixed frozen sections of rat liver showing the distribution pattern of CD68 in the liver lobule. Sections were labeled with an antibody to CD68 (red fluorescence) and stabilin-2 (Stab2, green fluorescence) and subjected to confocal laser scanning microscopy. Antibodies are listed in Table 1. Nuclei were stained with DAPI (blue).

Additional file 6. Immune regulatory factors. Excel file (.xIs) with the list of expressed genes annotated to cytokine receptor binding (GO:0005126), cytokine receptor activity (GO:0004896), complement activation (GO:0006956), or complement receptor activity (GO:0004875) in rat LSECS and KCs. The file shows their corresponding abundance in the RNA-seq datasets (RPKM values; worksheet named "Immunereg.factors_RPKM_RNAseq") and label-free proteomics datasets (iBAQ values; worksheet named "Immunereg.factors_iBAQ_LFP") along with differential expression analysis outputs. For visualization of the selected genes shown in Fig. $7, \log _{2}(R P K M+1)$ was used. 
Additional file 7. Genes annotated to antigen processing and presentation and lymphocyte co-stimulation. Excel file (.x/s) with the list of expressed genes associated with antigen processing and presentation (GO:0019882), and lymphocyte co-stimulation (GO:0031294) in LSECs and KCs. The file shows their corresponding abundance in the RNA-seq datasets (RPKM values; worksheet named "Immuneactivation_RPKM_RNAseq") and label-free proteomics datasets (iBAQ values; worksheet named "Immuneactivation_iBAQ_LFP") along with differential expression analysis outputs. For visualization of the selected genes and proteins shown in Fig. $8, \log _{2}(R P K M+1)$, and $\log _{2}(\mathrm{iBAQ}+1)$ were used.

Additional file 8. Immune histochemistry for CD31 and CD45, and controls for SE-1, CD31, CD45 flow cytometry experiments. a-b: Immune histochemistry of acetone-fixed frozen sections of rat liver showing the distribution pattern of stabilin-2, CD31 and CD45 in the liver lobule. a: Sections were labeled with antibodies to CD31 (red fluorescence) and stabilin-2 (Stab2, green fluorescence) and subjected to confocal laser scanning microscopy. CD31 stained all hepatic endothelia; in the sinusoids the CD31 staining overlapped with the stabilin-2 staining (arrows) b: Sections labeled with antibodies to CD45 (red fluorescence) and stabilin-2 (Stab2, green fluorescence). a-b: Pv, portal vein/venule. Antibodies are listed in Table 1. Nuclei were stained with DAPI (blue). c: The figure panel contains the contour profiles (of the singlet, small, low complexity, live-gated non-parenchymal liver cells) of the three single antibody staining controls on the different fluorophore channels used during the acquisition of the data in the flow cytometry experiment presented in Fig. 9. d: The figure contains the contour profiles of the three FMO controls and tests used to verify the gating used to interpret the experiment in Fig. 9.

Additional file 9. Analysis of microarray expression data obtained from Nolan et al. 2013 [35]. Excel file (.xls) with the comparative analysis of expression data obtained from a microarray profiling study of mouse (Mus musculus) primary microvascular endothelial cells, published by Nolan DJ, Ginsberg M, Israely E, Palikuqi B, Poulos MG, James D, et al. Molecular signatures of tissue-specific microvascular endothelial cell heterogeneity in organ maintenance and regeneration [35]. The microarray data was downloaded from the GEO public database-Series GSE47067. Title of dataset: In vivo endothelial cell heterogeneity. The first worksheet, named "Pairwise DGE (Nolan_2013)", shows pairwise analysis of the expression data of endothelial cells from different organs. The second worksheet, named "DAVID_liver specific genes", presents the DAVID enrichment analysis $[54,55]$ output of genes that were consistently significantly abundant in mouse liver sinusoidal endothelial cells (LSECS) in every pairwise comparison of LSECs with other microvascular endothelial cells in the dataset (Significance level: FDR $\leq 0.05$, and $\log _{2}$ fold change $\geq 1)$

Additional file 10. Ion Torrent sequencing results. Excel file (.xIs) summarizing the lon Torrent PGM sequencing results, including number of mapped sequences and average lengths.

\section{Abbreviations}

FDR: False discovery rate; GO: Gene ontology; GSEA: Gene set enrichment analysis; MACS: Magnetic-activated cell separation; KC: Kupffer cell; LSEC: Liver sinusoidal endothelial cell; NPC: Non-parenchymal liver cell; SR: Scavenger receptor

\section{Acknowledgements}

We thank Dr. Jack-Ansgar Bruun for help with the LC/MS-MS work.

\section{Authors' contributions}

Study concept and design: SB, RL, JS, SJ, PM, BS, IM, KS; acquisition of data: $\mathrm{SB}, \mathrm{RL}, \mathrm{JS}, \mathrm{KS}$; bioinformatics and statistical analysis: SB; analysis, interpretation, and visualization of data: $S B, R L, J S, B S, I M, K S$; drafting of manuscript: $S B, R L, J S, B S, K S$; critical revision of the manuscript for important intellectual content: SB, RL, JS, PM, SJ, IM, BS, KS; obtained funding: BS, PM, KS. All authors had access to the study data and have reviewed and approved the final manuscript.

\section{Funding}

This work was supported by the University of Tromsø (UiT) - The Arctic University of Norway, and by a grant from Tromsø Research Foundation to Bård Smedsrød. The study sponsor had no role in study design, collection, analysis or interpretation of data. The publication charges for this article have been funded by a grant from the publication fund of UiT The Arctic University of Norway.

\section{Availability of data and materials}

The datasets supporting the conclusions of this article are included within the article and its additional files. Additional data generated and analyzed during this study are available from the corresponding author on reasonable request.

The RNA-sequencing datasets generated and analysed during the current study are available in the NCBI Sequence Read Archive (SRA). SRA accession number to dataset: PRJNA574898. [https://www.ncbi.n/m.nih.gov/bioproject/ PRJNA574898/].

The mass spectrometry proteomics datasets generated and analysed during the current study are available in the ProteomeXchange Consortium PRIDE database. ProteomeXchange accession: PXD012080. [https://www.ebi.ac.uk/ pride/archive/projects/PXD012080].

\section{Ethics approval and consent to participate}

Experimental protocols using rats were approved by the competent institutional authority and the National Animal Research Authority at the Norwegian Food Safety Authority (Mattilsynet; Approval IDs: 4001, 8455, and 0817). Housing, handling and procedures were performed in compliance with Directive 2010/63/EU and the European Convention for the protection of Vertebrate Animals used for Experimental and Other Scientific Purposes (ETS 123, European Council). The experiments included are in vitro (euthanasia before tissue sampling) or terminal experiments where the anesthetized animal was euthanized during the surgical procedure, as described in Methods.

\section{Competing interests}

The authors declare no competing interests.

\section{Author details}

${ }^{1}$ Department of Medical Biology, Vascular Biology Research Group, University of Tromsø (UiT) -The Arctic University of Norway, Hansine Hansens veg 18, $\mathrm{N}-9037$ Tromsø, Norway. ${ }^{2}$ Faculty of Biosciences and Aquaculture, Nord University, Bodø, Norway. ${ }^{3}$ Department of Clinical Medicine, UiT -The Arctic University of Norway, Troms $\varnothing$, Norway.

Received: 16 February 2020 Accepted: 18 November 2020

Published online: 27 November 2020

\section{References}

1. Knolle PA, Wohlleber D. Immunological functions of liver sinusoidal endothelial cells. Cell Mol Immunol. 2016;13(3):347-53.

2. Shetty S, Lalor PF, Adams DH. Liver sinusoidal endothelial cells gatekeepers of hepatic immunity. Nat Rev Gastroenterol Hepatol. 2018;15(9): 555-67.

3. Bilzer M, Roggel F, Gerbes AL. Role of Kupffer cells in host defense and liver disease. Liver Int. 2006;26(10):1175-86.

4. van Furth R, Cohn ZA, Hirsch JG, Humphrey JH, Spector WG, Langevoort HL. The mononuclear phagocyte system: a new classification of macrophages, monocytes, and their precursor cells. Bull World Health Organ. 1972;46(6): 845-52.

5. Sørensen KK, McCourt P, Berg T, Crossley C, Le Couteur D, Wake K, et al. The scavenger endothelial cell: a new player in homeostasis and immunity. Am J Phys Regul Integr Comp Phys. 2012;303(12):R1217-30.

6. Seternes T, Sørensen K, Smedsrød B. Scavenger endothelial cells of vertebrates: a nonperipheral leukocyte system for high-capacity elimination of waste macromolecules. Proc Natl Acad Sci U S A. 2002;99(11):7594-7.

7. Eriksson S, Fraser JR, Laurent TC, Pertoft H, Smedsrød B. Endothelial cells are a site of uptake and degradation of hyaluronic acid in the liver. Exp Cell Res. 1983;144(1):223-8.

8. Skogh T, Blomhoff R, Eskild W, Berg T. Hepatic uptake of circulating lgG immune complexes. Immunology. 1985;55(4):585-94. 
9. Smedsrød B, Johansson S, Pertoft H. Studies in vivo and in vitro on the uptake and degradation of soluble collagen alpha $1(\mathrm{I})$ chains in rat liver endothelial and Kupffer cells. Biochem J. 1985;228(2):415-24.

10. Melkko J, Hellevik T, Risteli L, Risteli J, Smedsrød B. Clearance of NH2terminal propeptides of types I and III procollagen is a physiological function of the scavenger receptor in liver endothelial cells. J Exp Med. 1994;179(2):405-12.

11. Smedsrød B, Melkko J, Araki N, Sano H, Horiuchi S. Advanced glycation end products are eliminated by scavenger-receptor-mediated endocytosis in hepatic sinusoidal Kupffer and endothelial cells. Biochem J. 1997;322(Pt 2): 567-73.

12. Smedsrød B, Einarsson M. Clearance of tissue plasminogen activator by mannose and galactose receptors in the liver. Thromb Haemost. 1990;63(1): 60-6.

13. Smedsrød B, Melkko J, Risteli L, Risteli J. Circulating C-terminal propeptide of type I procollagen is cleared mainly via the mannose receptor in liver endothelial cells. Biochem J. 1990;271(2):345-50.

14. Dahl LB, Laurent TC, Smedsrød B. Preparation of biologically intact radioiodinated hyaluronan of high specific radioactivity: coupling of 125ltyramine-cellobiose to amino groups after partial N-deacetylation. Anal Biochem. 1988;175(2):397-407.

15. Smedsrød B, Pertoft H, Gustafson S, Laurent TC. Scavenger functions of the liver endothelial cell. Biochem J. 1990;266(2):313-27.

16. Sørensen KK, Simon-Santamaria J, McCuskey RS, Smedsrød B. Liver sinusoidal endothelial cells. Compr Physiol. 2015;5(4):1751-74.

17. Malovic I, Sørensen KK, Elvevold KH, Nedredal Gl, Paulsen S, Erofeev AV, et al. The mannose receptor on murine liver sinusoidal endothelial cells is the main denatured collagen clearance receptor. Hepatology. 2007;45(6):1454-61.

18. Elvevold K, Simon-Santamaria J, Hasvold H, McCourt P, Smedsrød B, Sørensen KK. Liver sinusoidal endothelial cells depend on mannose receptor-mediated recruitment of lysosomal enzymes for normal degradation capacity. Hepatology. 2008;48(6):2007-15.

19. Ganesan LP, Mohanty S, Kim J, Clark KR, Robinson JM, Anderson CL. Rapid and efficient clearance of blood-borne virus by liver sinusoidal endothelium. PLoS Pathog. 2011;7(9):e1002281.

20. Simon-Santamaria J, Rinaldo CH, Kardas P, Li R, Malovic I, Elvevold K, et al. Efficient uptake of blood-borne BK and JC polyomavirus-like particles in endothelial cells of liver sinusoids and renal vasa recta. PLoS One. 2014;9(11):e111762.

21. Mates JM, Yao Z, Cheplowitz AM, Suer O, Phillips GS, Kwiek JJ, et al. Mouse liver sinusoidal endothelium eliminates HIV-like particles from blood at a rate of 100 million per minute by a second-order kinetic process. Front Immunol. 2017;8(35):35.

22. Simon-Santamaria J, Malovic I, Warren A, Oteiza A, Le Couteur D, Smedsrød $B$, et al. Age-related changes in scavenger receptor-mediated endocytosis in rat liver sinusoidal endothelial cells. J Gerontol A Biol Sci Med Sci. 2010; 65(9):951-60.

23. Godfrey C, Desviat LR, Smedsrød B, Pietri-Rouxel F, Denti MA, Disterer P, et al. Delivery is key: lessons learnt from developing splice-switching antisense therapies. EMBO Mol Med. 2017;9(5):545-57.

24. McCourt PA, Smedsrød BH, Melkko J, Johansson S. Characterization of a hyaluronan receptor on rat sinusoidal liver endothelial cells and its functional relationship to scavenger receptors. Hepatology. 1999;30(5):1276-86.

25. Politz O, Gratchev A, McCourt PA, Schledzewski K, Guillot P, Johansson S, et al. Stabilin-1 and -2 constitute a novel family of fasciclin-like hyaluronan receptor homologues. Biochem J. 2002;362(Pt 1):155-64.

26. Mousavi SA, Sporstol M, Fladeby C, Kjeken R, Barois N, Berg T. Receptormediated endocytosis of immune complexes in rat liver sinusoidal endothelial cells is mediated by FcgammaRIllb2. Hepatology. 2007:46(3):871-84.

27. Uhrig A, Banafsche R, Kremer M, Hegenbarth S, Hamann A, Neurath M, et al. Development and functional consequences of LPS tolerance in sinusoidal endothelial cells of the liver. J Leukoc Biol. 2005;77(5):626-33.

28. Martin-Armas M, Simon-Santamaria J, Pettersen I, Moens U, Smedsrød B, Sveinbjornsson B. Toll-like receptor 9 (TLR9) is present in murine liver sinusoidal endothelial cells (LSECS) and mediates the effect of CpGoligonucleotides. J Hepatol. 2006;44(5):939-46.

29. Wu J, Meng $Z$, Jiang $M$, Zhang $E$, Trippler $M$, Broering $R$, et al. Toll-like receptor-induced innate immune responses in non-parenchymal liver cells are cell type-specific. Immunology. 2010;129(3):363-74.

30. Knolle PA, Germann T, Treichel U, Uhrig A, Schmitt E, Hegenbarth S, et al. Endotoxin down-regulates $T$ cell activation by antigen-presenting liver sinusoidal endothelial cells. J Immunol. 1999;162(3):1401-7.
31. Limmer A, Ohl J, Kurts C, Ljunggren $H G$, Reiss $Y$, Groettrup $M$, et al. Efficient presentation of exogenous antigen by liver endothelial cells to CD8+ T cells results in antigen-specific T-cell tolerance. Nat Med. 2000;6(12):1348-54.

32. Limmer $A$, Ohl J, Wingender $G$, Berg $M$, Jungerkes $F$, Schumak $B$, et al. Cross-presentation of oral antigens by liver sinusoidal endothelial cells leads to CD8 T cell tolerance. Eur J Immunol. 2005;35(10):2970-81.

33. Steffan AM, Gendrault JL, McCuskey RS, McCuskey PA, Kirn A. Phagocytosis, an unrecognized property of murine endothelial liver cells. Hepatology. 1986;6(5):830-6.

34. Chi JT, Chang HY, Haraldsen G, Jahnsen FL, Troyanskaya OG, Chang DS, et al. Endothelial cell diversity revealed by global expression profiling. Proc Natl Acad Sci U S A. 2003;100(19):10623-8.

35. Nolan DJ, Ginsberg M, Israely E, Palikuqi B, Poulos MG, James D, et al. Molecular signatures of tissue-specific microvascular endothelial cell heterogeneity in organ maintenance and regeneration. Dev Cell. 2013;26(2): 204-19.

36. DeLeve LD, Maretti-Mira AC. Liver sinusoidal endothelial cell: an update. Semin Liver Dis. 2017;37(4):377-87.

37. Elvevold K, Smedsrød B, Martinez I. The liver sinusoidal endothelial cell: a cell type of controversial and confusing identity. Am J Physiol Gastrointest Liver Physiol. 2008;294(2):G391-400.

38. Xie G, Wang L, Wang X, Wang L, DeLeve LD. Isolation of periportal, midlobular, and centrilobular rat liver sinusoidal endothelial cells enables study of zonated drug toxicity. Am J Physiol Gastrointest Liver Physiol. 2010; 299(5):G1204-10.

39. Geraud C, Schledzewski K, Demory A, Klein D, Kaus M, Peyre F, et al. Liver sinusoidal endothelium: a microenvironment-dependent differentiation program in rat including the novel junctional protein liver endothelial differentiation-associated protein-1. Hepatology. 2010;52(1):313-26.

40. Martinez I, Nedredal Gl, Øie Cl, Warren A, Johansen O, Le Couteur DG, et al. The influence of oxygen tension on the structure and function of isolated liver sinusoidal endothelial cells. Comp Hepatol. 2008;7:4.

41. Azimifar SB, Nagaraj N, Cox J, Mann M. Cell-type-resolved quantitative proteomics of murine liver. Cell Metab. 2014;20(6):1076-87.

42. Ding C, Li Y, Guo F, Jiang Y, Ying W, Li D, et al. A cell-type-resolved liver proteome. Mol Cell Proteomics. 2016;15(10):3190-202.

43. Tokairin T, Nishikawa Y, Doi Y, Watanabe H, Yoshioka T, Su M, et al. A highly specific isolation of rat sinusoidal endothelial cells by the immunomagnetic bead method using SE-1 monoclonal antibody. J Hepatol. 2002;36(6):725-33.

44. Ohmura T, Enomoto K, Satoh H, Sawada N, Mori M. Establishment of a novel monoclonal antibody, SE-1, which specifically reacts with rat hepatic sinusoidal endothelial cells. J Histochem Cytochem. 1993;41(8):1253-7.

45. March S, Hui EE, Underhill GH, Khetani S, Bhatia SN. Microenvironmental regulation of the sinusoidal endothelial cell phenotype in vitro. Hepatology. 2009;50(3):920-8.

46. Yoshida M, Nishikawa Y, Omori Y, Yoshioka T, Tokairin T, McCourt P, et al. Involvement of signaling of VEGF and TGF-beta in differentiation of sinusoidal endothelial cells during culture of fetal rat liver cells. Cell Tissue Res. 2007;329(2):273-82

47. Geraud C, Koch PS, Zierow J, Klapproth K, Busch K, Olsavszky V, et al. GATA4dependent organ-specific endothelial differentiation controls liver development and embryonic hematopoiesis. J Clin Invest. 2017;127(3):1099-114.

48. Low TY, van Heesch S, van den Toorn H, Giansanti P, Cristobal A, Toonen P, et al. Quantitative and qualitative proteome characteristics extracted from in-depth integrated genomics and proteomics analysis. Cell Rep. 2013;5(5): 1469-78.

49. Subramanian A, Tamayo P, Mootha VK, Mukherjee S, Ebert BL, Gillette MA, et al. Gene set enrichment analysis: a knowledge-based approach for interpreting genome-wide expression profiles. Proc Natl Acad Sci U S A. 2005;102(43):15545-50.

50. Mootha VK, Lindgren CM, Eriksson KF, Subramanian A, Sihag S, Lehar J, et al. PGC-1alpha-responsive genes involved in oxidative phosphorylation are coordinately downregulated in human diabetes. Nat Genet. 2003;34(3):267-73.

51. Ashburner M, Ball CA, Blake JA, Botstein D, Butler H, Cherry JM, et al. Gene ontology: tool for the unification of biology. The Gene Ontology Consortium. Nat Genet. 2000;25(1):25-9.

52. The Gene Ontology C. The gene ontology resource: 20 years and still GOing strong. Nucleic Acids Res. 2019:47(D1):D330-D8.

53. Liberzon A, Birger C, Thorvaldsdóttir H, Ghandi M, Mesirov Jill P, Tamayo P. The molecular signatures database Hallmark gene set collection. Cell Syst. 2015;1(6):417-25. 
54. Huang da W, Sherman BT, Lempicki RA. Systematic and integrative analysis of large gene lists using DAVID bioinformatics resources. Nat Protoc 2009; 4(1):44-57.

55. Huang DW, Sherman BT, Lempicki RA. Bioinformatics enrichment tools: paths toward the comprehensive functional analysis of large gene lists. Nucleic Acids Res. 2009;37(1):1-13.

56. Mortazavi A, Williams BA, McCue K, Schaeffer L, Wold B. Mapping and quantifying mammalian transcriptomes by RNA-Seq. Nat Methods. 2008;5(7): 621-8.

57. Malerod L, Juvet $\mathrm{K}$, Gjoen T, Berg T. The expression of scavenger receptor class B, type I (SR-BI) and caveolin-1 in parenchymal and nonparenchymal liver cells. Cell Tissue Res. 2002;307(2):173-80.

58. Strauss O, Phillips A, Ruggiero K, Bartlett A, Dunbar PR. Immunofluorescence identifies distinct subsets of endothelial cells in the human liver. Sci Rep. 2017;7:44356.

59. Li R, Oteiza A, Sørensen KK, McCourt P, Olsen R, Smedsrød B, et al. Role of liver sinusoidal endothelial cells and stabilins in elimination of oxidized lowdensity lipoproteins. Am J Physiol Gastrointest Liver Physiol. 2011;300(1): G71-81.

60. Geraud C, Evdokimov K, Straub BK, Peitsch WK, Demory A, Dorflinger Y, et al. Unique cell type-specific junctional complexes in vascular endothelium of human and rat liver sinusoids. PLoS One. 2012;7(4): e34206.

61. Liu W, Tang L, Zhang G, Wei H, Cui Y, Guo L, et al. Characterization of a novel C-type lectin-like gene, LSECtin: demonstration of carbohydrate binding and expression in sinusoidal endothelial cells of liver and lymph node. J Biol Chem. 2004:279(18):18748-58.

62. Aizarani N, Saviano A, Sagar, Mailly L, Durand S, Herman JS, et al. A human liver cell atlas reveals heterogeneity and epithelial progenitors. Nature. 2019; 572(7768):199-204.

63. Stutchfield BM, Antoine DJ, Mackinnon AC, Gow DJ, Bain CC, Hawley CA, et al. CSF1 restores innate immunity after liver injury in mice and serum levels indicate outcomes of patients with acute liver failure. Gastroenterology. 2015;149(7):1896-909 e14

64. Xu H, Cao D, Guo G, Ruan Z, Wu Y, Chen Y, et al. Diagn Pathol. 2012;7:142.

65. Scoazec JY, Feldmann G. In situ immunophenotyping study of endothelial cells of the human hepatic sinusoid: results and functional implications. Hepatology. 1991;14(5):789-97.

66. Harb R, Xie G, Lutzko C, Guo Y, Wang X, Hill CK, et al. Bone marrow progenitor cells repair rat hepatic sinusoidal endothelial cells after liver injury. Gastroenterology. 2009;137(2):704-12.

67. DeLeve LD, Wang X, Hu L, McCuskey MK, McCuskey RS. Rat liver sinusoidal endothelial cell phenotype is maintained by paracrine and autocrine regulation. Am J Physiol Gastrointest Liver Physiol. 2004; 287(4):G757-63

68. MacParland SA, Liu JC, Ma XZ, Innes BT, Bartczak AM, Gage BK, et al. Single cell RNA sequencing of human liver reveals distinct intrahepatic macrophage populations. Nat Commun. 2018;9(1):4383.

69. Lalor PF, Lai WK, Curbishley SM, Shetty S, Adams DH. Human hepatic sinusoidal endothelial cells can be distinguished by expression of phenotypic markers related to their specialised functions in vivo. World J Gastroenterol. 2006;12(34):5429-39.

70. Poisson J, Lemoinne S, Boulanger C, Durand F, Moreau R, Valla D, et al. Liver sinusoidal endothelial cells: physiology and role in liver diseases. J Hepatol. 2017;66(1):212-27.

71. Lynch RW, Hawley CA, Pellicoro A, Bain CC, Iredale JP, Jenkins SJ. An efficient method to isolate Kupffer cells eliminating endothelial cell contamination and selective bias. J Leukoc Biol. 2018;104(3):579-86.

72. Bonnardel J, T'Jonck W, Gaublomme D, Browaeys R, Scott CL, Martens L, et al. Stellate Cells, Hepatocytes, and Endothelial Cells Imprint the Kupffer Cell Identity on Monocytes Colonizing the Liver Macrophage Niche. Immunity. 2019;51(4):638-54 e9.

73. Mouta Carreira C, Nasser SM, di Tomaso E, Padera TP, Boucher Y, Tomarev $\mathrm{SI}$, et al. LYVE-1 is not restricted to the lymph vessels: expression in normal liver blood sinusoids and down-regulation in human liver cancer and cirrhosis. Cancer Res. 2001;61(22):8079-84.

74. Ishikawa T, Yokoyama H, Matsuura T, Fujiwara Y. Fc gamma Rllb expression levels in human liver sinusoidal endothelial cells during progression of non-alcoholic fatty liver disease. PLoS One. 2019;14(1): e0211543.
75. Smedsrød B, Pertoft H, Eggertsen G, Sundstrom C. Functional and morphological characterization of cultures of Kupffer cells and liver endothelial cells prepared by means of density separation in Percoll, and selective substrate adherence. Cell Tissue Res. 1985;241(3):639-49.

76. Bouwens L, Baekeland M, de Zanger R, Wisse E. Quantitation, tissue distribution and proliferation kinetics of kupffer cells in normal rat liver. Hepatology. 1986;6(4):718-22.

77. Guillot A, Tacke F. Liver macrophages: old dogmas and new insights. Hepatol Commun. 2019;3(6):730-43.

78. Nishiyama K, Nakashima H, Ikarashi M, Kinoshita M, Nakashima M, Aosasa S, et al. Mouse CD11b+Kupffer Cells Recruited from Bone Marrow Accelerate Liver Regeneration after Partial Hepatectomy. PLoS One. 2015;10(9): e0136774 e.

79. Krenkel O, Tacke F. Liver macrophages in tissue homeostasis and disease. Nat Rev Immunol. 2017; 17(5):306-21.

80. Helmy KY, Katschke KJ Jr, Gorgani NN, Kljavin NM, Elliott JM, Diehl L, et al. CRlg: A macrophage complement receptor required for phagocytosis of circulating pathogens. Cell. 2006;124(5):915-27.

81. Zeng Z, Surewaard BGJ, Wong CHY, Geoghegan JA, Jenne CN, Kubes P. CRlg functions as a macrophage pattern recognition receptor to directly bind and capture blood-borne gram-positive bacteria. Cell Host Microbe. 2016;20(1):99-106

82. Naito M, Hasegawa G, Ebe $Y$, Yamamoto T. Differentiation and function of Kupffer cells. Med Electron Microscopy. 2004;37(1):16-28.

83. Scott $C L$, Zheng F, De Baetselier P, Martens L, Saeys Y, De Prijck S, et al. Bone marrow-derived monocytes give rise to self-renewing and fully differentiated Kupffer cells. Nat Commun. 2016;7.

84. Wang L, Wang X, Xie G, Wang L, Hill CK, DeLeve LD. Liver sinusoidal endothelial cell progenitor cells promote liver regeneration in rats. J Clin Invest. 2012;122(4):1567-73.

85. Martens JH, Kzhyshkowska J, Falkowski-Hansen M, Schledzewski K, Gratchev A, Mansmann U, et al. Differential expression of a gene signature for scavenger/lectin receptors by endothelial cells and macrophages in human lymph node sinuses, the primary sites of regional metastasis. J Pathol. 2006; 208(4):574-89.

86. Hubbard AL, Wilson G, Ashwell G, Stukenbrok H. An electron microscope autoradiographic study of the carbohydrate recognition systems in rat liver. I. Distribution of 1251-ligands among the liver cell types. J Cell Biol. 1979; 83(1):47-64

87. Dalen DPP-V, De Leeuw AM, Brouwer A, Knook DL. Rat liver endothelial cells have a greater capacity than kupffer cells to endocytose $\mathrm{N}$ acetylglucosamine- and mannose-terminated glycoproteins. Hepatology. 1987;7(4):672-9.

88. Bijsterbosch MK, Donker W, van de Bilt H, van Weely S, van Berkel TJ, Aerts JM. Quantitative analysis of the targeting of mannose-terminal glucocerebrosidase. Predominant uptake by liver endothelial cells. Eur $J$ Biochem. 1996;237(2):344-9.

89. Kindberg GM, Stang E, Andersen K, Roos N, Berg T. Intracellular transport of endocytosed proteins in rat liver endothelial cells. Biochem J. 1990;270(1): 205-11.

90. Øie Cl, Appa RS, Hilden I, Petersen HH, Gruhler A, Smedsrød B, et al. Rat liver sinusoidal endothelial cells (LSECS) express functional low density lipoprotein receptor-related protein-1 (LRP-1). J Hepatol. 2011;55(6):1346-52.

91. Zimmermann N, Hogan SP, Mishra A, Brandt EB, Bodette TR, Pope SM, et al. Murine eotaxin-2: a constitutive eosinophil chemokine induced by allergen challenge and IL-4 overexpression. J Immunol. 2000;165(10):5839-46.

92. Miles A, Liaskou E, Eksteen B, Lalor PF, Adams DH. CCL25 and CCL28 promote alpha4 beta7-integrin-dependent adhesion of lymphocytes to MAdCAM-1 under shear flow. Am J Physiol Gastrointest Liver Physiol. 2008; 294(5):G1257-67.

93. Martinez I, Sveinbjornsson B, Vidal-Vanaclocha F, Asumendi A, Smedsrød B. Differential cytokine-mediated modulation of endocytosis in rat liver endothelial cells. Biochem Biophys Res Commun. 1995;212(1):235-41.

94. Liu Y, Gardner CR, Laskin JD, Laskin DL. Classical and alternative activation of rat hepatic sinusoidal endothelial cells by inflammatory stimuli. Exp Mol Pathol. 2013:94(1):160-7.

95. Schildberg FA, Hegenbarth SI, Schumak B, Scholz K, Limmer A, Knolle PA. Liver sinusoidal endothelial cells veto CD8 T cell activation by antigenpresenting dendritic cells. Eur J Immunol. 2008;38(4):957-67.

96. Knolle PA, Gerken G. Local control of the immune response in the liver. Immunol Rev. 2000;174:21-34. 
97. Onoe T, Ohdan H, Tokita D, Shishida M, Tanaka Y, Hara H, et al. Liver sinusoidal endothelial cells tolerize T cells across MHC barriers in mice. J Immunol. 2005;175(1):139-46.

98. Carambia A, Freund B, Schwinge D, Heine M, Laschtowitz A, Huber S, et al. TGF-beta-dependent induction of CD4(+)CD25(+)Foxp3(+) Tregs by liver sinusoidal endothelial cells. J Hepatol. 2014;61(3):594-9.

99. Connolly MK, Bedrosian AS, Malhotra A, Henning JR, Ibrahim J, Vera V, et al. In hepatic fibrosis, liver sinusoidal endothelial cells acquire enhanced immunogenicity. J Immunol. 2010;185(4):2200-8.

100. Smedsrød B, Pertoft H. Preparation of pure hepatocytes and reticuloendothelial cells in high yield from a single rat liver by means of Percoll centrifugation and selective adherence. J Leukoc Biol. 1985;38(2): 213-30.

101. Zerbino DR, Achuthan P, Akanni W, Amode MR, Barrell D, Bhai J, et al. Ensembl 2018. Nucleic Acids Res. 2018;46(D1):D754-D61.

102. Law CW, Alhamdoosh M, Su S, Dong X, Tian L, Smyth GK, et al. RNA-seq analysis is easy as 1-2-3 with limma, Glimma and edgeR. F1000Res. 2016;5: 1408.

103. Ritchie ME, Phipson B, Wu D, Hu Y, Law CW, Shi W, et al. limma powers differential expression analyses for RNA-sequencing and microarray studies. Nucleic Acids Res. 2015;43(7):e47.

104. Cox J, Mann M. MaxQuant enables high peptide identification rates, individualized p.p.b.-range mass accuracies and proteome-wide protein quantification. Nat Biotechnol. 2008;26(12):1367-72.

105. Schwanhausser B, Busse D, Li N, Dittmar G, Schuchhardt J, Wolf J, et al. Global quantification of mammalian gene expression control. Nature. 2011; 473(7347):337-42.

\section{Publisher's Note}

Springer Nature remains neutral with regard to jurisdictional claims in published maps and institutional affiliations.

Ready to submit your research? Choose BMC and benefit from:

- fast, convenient online submission

- thorough peer review by experienced researchers in your field

- rapid publication on acceptance

- support for research data, including large and complex data types

- gold Open Access which fosters wider collaboration and increased citations

- maximum visibility for your research: over $100 \mathrm{M}$ website views per year

At BMC, research is always in progress.

Learn more biomedcentral.com/submissions 